\title{
Copyright
}

by

Christine Eve Fiestas

2008 
The Dissertation Committee for Christine Eve Fiestas Certifies that this is the approved version of the following dissertation:

\section{The Dynamic Assessment of Narratives: A Bilingual Study}

\section{Committee:}

Elizabeth Peña , Supervisor

Ronald Gillam, Co-Supervisor

Lisa Bedore

Catharine Echols

Diane Schallert 
The Dynamic Assessment of Narratives: A Bilingual Study

by

Christine Eve Fiestas, B.A., M.A.

\author{
Dissertation \\ Presented to the Faculty of the Graduate School of \\ The University of Texas at Austin \\ in Partial Fulfillment \\ of the Requirements \\ for the Degree of
}

Doctor of Philosophy

The University of Texas at Austin

December, 2008 


\section{Dedication}

This dissertation is dedicated to the children of Del Valle and Pflugerville school districts, The Wilbur and Fiestas’ extended families, and good friends from Maine, Austin, Vermont, Florida, Budapest, New Zealand, Sweden, Nigeria and Perú who all encouraged me to complete this study. I also want to thank Juan, Seth, Manuel and finally Inés who all took on this project in their own ways. Thanks for your support and for believing in me. 


\section{Acknowledgements}

I would like to acknowledge and thank and my dissertation committee for all of your feedback, knowledge, and time. Thanks Liz for taking time out over your summer vacation to read numerous versions of this manuscript, and for always inspiring me to write better, and to Lisa for all of your bright and practical suggestions. Thanks to Ron for your inspiration to do an intervention study and for you research and narrative expertise. Thanks also to Dr. Schallert for your enthusiasm and for making me really take time out to think about the factors of comprehension and for your interest in the study, and to Dr. Echols for the exposure to the language development literature in psychology and the “cognitive connection”. Thanks to Barbara Noble, John Davis, and Maria Resendiz for your help in recruiting participants and to the small army of graduate students and undergraduates in CSD who helped test, transcribe, perform the MLE's, score, and stay organized for the project. Finally, thanks to the teachers and children for participating and for allowing us to work with you. 


\title{
The Dynamic Assessment of Narratives: A Bilingual Study
}

Publication No.

\author{
Christine Eve Fiestas, Ph.D. \\ The University of Texas at Austin, 2008
}

Supervisor: Elizabeth D. Peña

Co-Supervisor: Ronald B. Gillam

This three-part study explores an application of the dynamic assessment of narratives in a bilingual Spanish and English-speaking early elementary population as a preliminary study of bilingual children's response to a short-term intervention. Dynamic assessment has been used successfully to differentiate culturally diverse monolingual children with language impairment from their typically developing peers. In order to extend this assessment measure to bilinguals, specifically Spanish and English-speaking children, the effects of the language of intervention and the language of production was explored. Profiles of bilingual children's narratives with and without impairment and their differential responses has not been well documented in both languages. Thus, narrative profiles and from pre to post intervention changes were compared for typically developing and language-impaired children. The first study examined whether parallel stories were elicited within languages using two books. The second study explored the effects of the language of intervention and the language of story production on narrative performance, and the transfer of narratives skills across languages using the dynamic assessment paradigm. The third study examined children's performance with and 
without language impairment pre and post mediated learning experience in comparison to a non-intervention control group. Results from study one indicated that children told parallel stories for the two books within each language. Findings from study two indicated that children's stories in Spanish were stronger overall, and children's performance did not differ as a function of intervention in Spanish vs. English. Children demonstrated transfer of narrative macrostructure across both languages. Finally, study three indicated that the children who were typically developing demonstrated a greater amount of pretest to posttest gain as compared to children in the language impaired and control groups. The typically developing children were rated as more modifiable in comparison to those with language impairment. 


\section{Table of Contents}

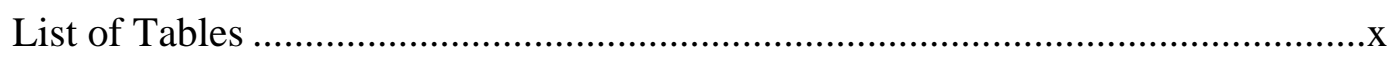

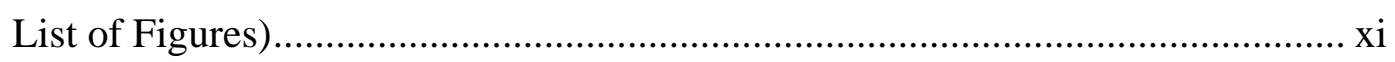

Chapter 1 Review of the Literature...............................................................

The Dynamic Assessment of Narratives ....................................................1

A Functional Model of Bilingual Input and Use ........................................4

Narrative Skills and Cognition..................................................................6

Narrative Universals, Differences, and Development ................................9

Differential Profiles of Bilingual Narratives...............................................11

Narrative Production in Children with LI ..................................................15

Questions of the Current Study .............................................................18

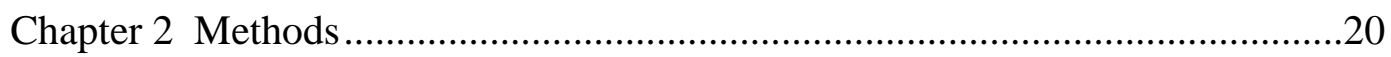

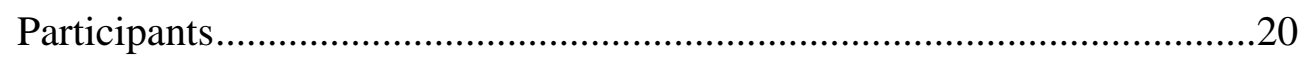

Subjects with typical language development ................................21

Subjects with language impairment .............................................22

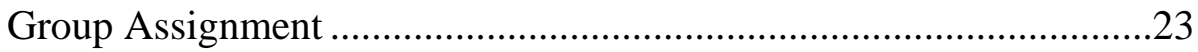

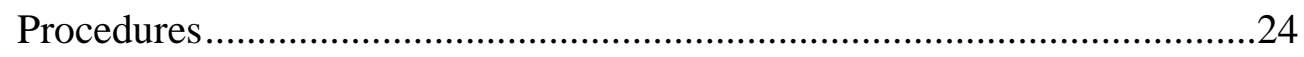

Dynamic Assessment ..............................................................24

Narrative Pretest................................................................24

Mediated Learning Experiences ...............................................24

Narrative Posttest .................................................................27

Transcription .........................................................................28

Narrative Item Scoring ...........................................................28

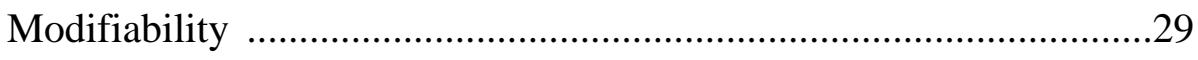

Reliability .........................................................................29

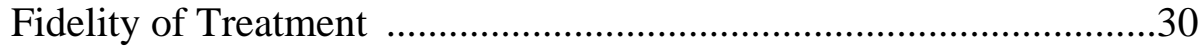

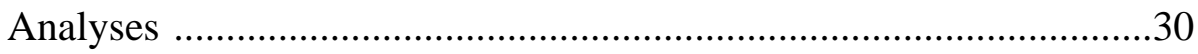

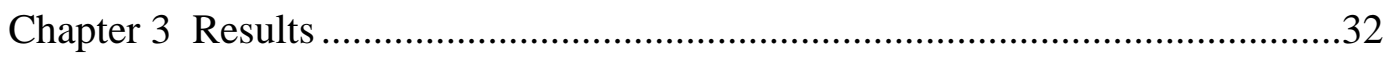

Study One: Parallel Stories Analysis ....................................................32

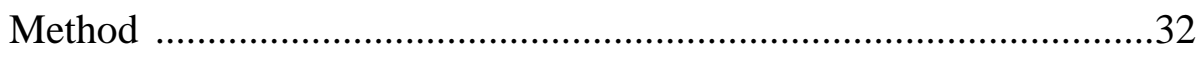

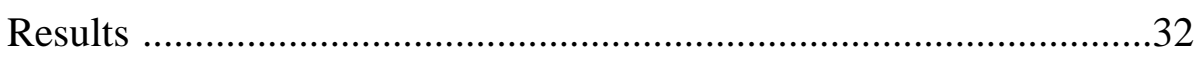




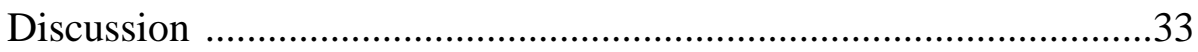

Study Two: Language Effects and Transfer ...................................................33

Method

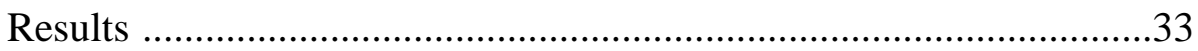

Language of Production Effects...................................................35

Language of Intervention Effects..................................................38

Transfer Effects: The Language of Mediation and Production ..40

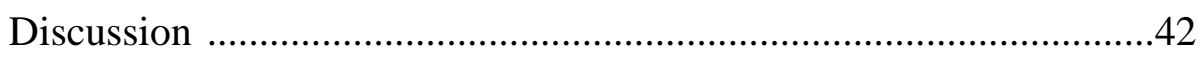

Study Three: Language Ability Differences ...................................................44

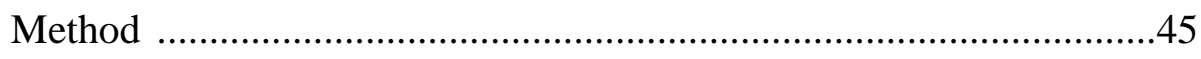

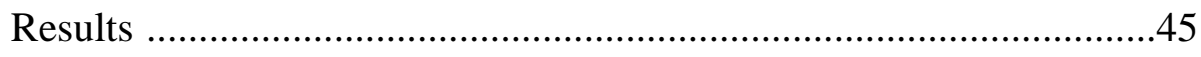

Language ability effects............................................................45

Modifiability .............................................................................

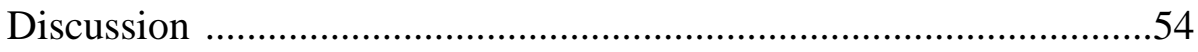

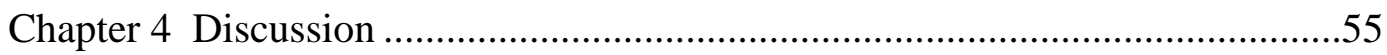

Language of Production, Intervention, and Transfer .......................................55

Language Ability Differences.....................................................................58

Implications for Testing, Limitations, and Future Directions.........................50

Appendix A MLE Script in English................................................................63

Appendix B MLE Script in Spanish .................................................................66

Appendix C Mediated Learning Observation ........................................................69

Appendix D Sample Pretest and Posttest Transcripts in English and Spanish.....70

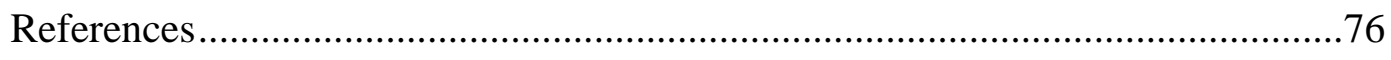

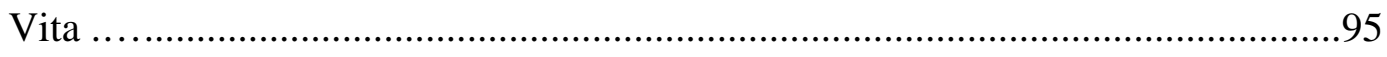




\section{List of Tables}

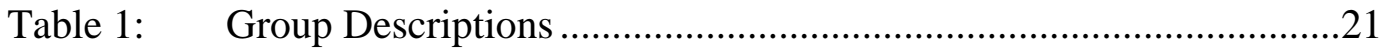

Table 2: Group language raw scores and cognitive test scores......................22

Table 3: $\quad$ Research Design......................................................................23

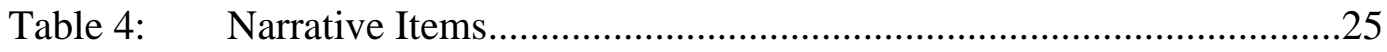

Table 5: $\quad$ Parallel Forms Reliability .............................................................33

Table 6: $\quad$ Mean Story and Productive Measures for Control, TD and LI Groups

for English and Spanish Pretest and Posttest .................................38

Table 7: $\quad$ Mean Conceptual Scores for Story Measures for Control, TD and

LI Groups for English and Spanish............................................40

Table 8: Gain Scores for Story and Productive Measures for Spanish and

English Stories Matched and Unmatched to the Language of

Intervention for TD and LI Groups.............................................43 


\section{List of Figures}

Figure 1: $\quad$ Pretest and Posttest Total Scores By Group ...................................46

Figure 2: $\quad$ Pretest and Posttest Story Components Scores By Group ................48

Figure 3: $\quad$ Pretest and Posttest Story Ideas and Language Scores By Group n .48

Figure 4: $\quad$ Pretest and Posttest Episode Structure Scores By Group .................49

Figure 5: $\quad$ Pretest and Posttest Plan Scores By Group.....................................51

Figure 6: $\quad$ Pretest and Posttest Total Number of Different Words By Group ...51

Figure 7: $\quad$ Pretest and Posttest Mean Number of Clauses per Utterance By

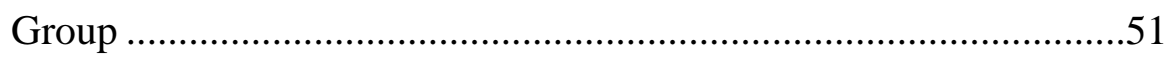

Figure 8: $\quad$ Pretest and Posttest Mean Length of Utterance in words by Group.52

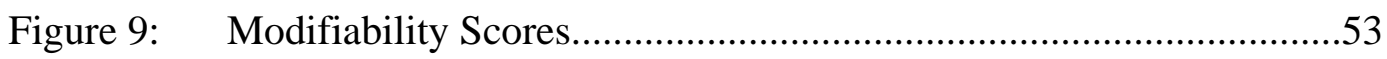

Figure 10: Modifiability Scores By Language of Intervention .........................53 


\section{Chapter 1: Review of the Literature}

Dynamic assessment (DA) is a process-oriented approach to assessment that uses a test-teach-retest model to evaluate change during a brief period of intervention. Application of DA have been applied successfully to describe the language learning potential of children referred for assessment and to differentiate between language minority children with and without language impairment (LI) (Peña et. al., 2006; Peña, Iglesias \& Lidz, 2001; Peña, Quinn \& Iglesias, 1992; Stubbe Kester, Peña, \& Gillam, 2001; Ukrainetz, Harpell, Walsh \& Coyle, 2000). While DA has been proposed for language minority children including bilinguals (Gutierrez-Clellen, 2004; GutierrezClellen \& Quinn, 1993; Laing \& Kamhi, 2003; Patterson \& Pearson, 2004; Kohnert, 2008) its application to bilinguals has yet to be examined systematically.

\section{THE DYNAMIC ASSESSMENT OF NARRATIVES}

Narrative assessment has the potential to provide language performance data that has ecological, cultural, and linguistic validity. Children may come to the table with very different socialization experiences based on cultural and linguistic differences. Experience with talking about stories, or retelling events may be different for children from diverse backgrounds (Gutierrez-Clellen, Peña, \& Quinn, 1995). Despite children’s differences in culture and experience telling stories, research has documented change in culturally and linguistically diverse children's narrative performance.

DA emphasizes the cognitive tools related to language use. In an application of DA to improve narrative skills, the emphasis is on including and organizing the components of narratives by teaching cognitive strategies such as attention, comparison, organization, discrimination, inferencing, and describing cause and effect. In the above narrative application of dynamic assessment (Peña et al., 2006), CLD children who did 
not efficiently learn strategies during mediation to improve their stories were likely to be children with underlying language learning difficulties (Peña, Resendiz, \& Gillam, 2007).

Peña et al. (2006) examined the classification accuracy of the dynamic assessment of narratives comparing $1^{\text {st }}$ and $2^{\text {nd }}$ grade culturally and linguistically diverse groups of children with and without language impairment, and a no-treatment control group. Children from different cultural backgrounds improved their narrative skills using DA. Children did not demonstrate cultural or linguistic differences at posttest. In comparison to children with LI, typically developing children from diverse backgrounds showed greater response to intervention. Children with LI made some gains, but these gains were not as robust. In addition, clinician's ratings of children's modifiability revealed that children with typical language were more modifiable to the intervention, whereas the children with language impairment required more support from the clinician. The modifiability scores provided the most accurate measure of language impairment used in the classification analysis. Further, posttest values of narrative micro and macrostructure yielded better specificity and sensitivity values than pretest to classify children with language impairment.

Bilingual children's narrative productions provide the opportunity to study the interface of language, culture, and cognitive processes (e.g. mental models of story). By testing the effects of short-term intervention in the first language or second language for bilingual children, we can expand our understanding of what aspects of language in a narrative context will transfer or not. Cognitively based mediation, such as that used in DA, is assumed to support change in children's use of strategies and helps them employ cognitive tools which underlie the process of language learning. As such, transfer of these skills would be more likely across languages than a focusing on specific language forms. In a comparison of direct instruction and mediated learning using high and low context materials to teach children to label items, Stubbe et al. (2001) targeted the cognitive functions that related to labeling (e.g., comparison, distinctive features, and 
classification). Intentionality, transcendence, competence, and mediation of meaning were incorporated in the two mediated learning (MLE) conditions while the direct instruction condition used exposure and behavioral reinforcement without the metacognitive components. Children in the MLE conditions made the most significant gains. Because of the focus on the underlying cognitive skills, the MLE approach may lead to greater transfer to other tasks. A short-term intervention such as in the type of cognitively based mediated instruction used in DA provides an opportunity to observe learning and transfer of the language skills involved in narrative production. Because DA emphasizes the cognitive tools that underlie language learning, there is the potential for the transfer of between languages of global narrative skills as opposed to focusing on specific language forms.

Dynamic assessment likely can be utilized to identify patterns of pretest to posttest change for bilingual children with and without language impairment. The utility of this approach for bilingual children remains to be investigated, particularly those from Latino backgrounds, who are one of the largest linguistic minority groups in the U.S. From a practical perspective, examination of change in language use and error patterns in bilingual children with and without language impairment (LI) will provide important data on language learning in bilingual children. To determine the feasibility of DA of narratives, of interest is an investigation of whether two narrative stimuli will yield parallel stories within Spanish and within English for bilingual children, Stories used to generate pretest and posttest stories yielded parallel stories for English-speaking children in Peña et al.'s study (2006). Potential differences in the language of story production, and whether the language of intervention influences development in the untrained language are questions that need to be explored. Clinically, the questions of expected change and language(s) of learning have implications for guiding decisions about the language of intervention for bilingual children with LI. Therefore, a usage-based functional model is useful to guide predictions about the language of intervention, and to 
understand the interplay of the first language and second language in the process of second language acquisition.

\section{A FUNCTIONAL MODEL OF BILINGUAL LANGUAGE INPUT AND USE}

Recent accounts of language acquisition have examined the role of input in learning (Nelson et al., 1990, 1993; Tomasello, 1999, 2003). For children in bilingual environments who are learning a second language after a first, the interaction of both development and input on language learning is of interest because children with different amounts of exposure may exhibit different performance in each language on tasks such as telling a story. Children learning English as a second language may demonstrate errors at an age whereas monolingual learners are making relatively few errors.

The competition model (MacWhinney, 1987; 1992; 1997) and more recently the unified model (MacWhinney, 2005) have been proposed to explain the process of first and second language acquisition respectively. The unified model is a functionalist approach developed to account for the interactions of language for second language acquisition. According to this model, learners rely on cues from input exposure for the acquisition of language(s). Cues have different strengths based on their reliability in the language environment. Cues that are frequent in the input and lead to correct performance

are determined to be reliable and valid. As such, learners rely on these cues to learn the rules of language.

Cues have different strengths across languages (reviewed in MacWhinney, 1997). For instance, we can compare cue validity in Spanish and English to identify the subject of a sentence. In English, we would rely on word order to identify the subject in the preverbal position (agent+action+object). Word order is a reliable and valid cue in English. In comparison, the validity of this cue is minimized in Spanish, a language with less strict word order and heavier reliance on verb morphology cues to identify the subject of a sentence. 
When learning a second language, children may be faced with cues that are consistent across languages and with cues that compete across languages. Cues that are the same across languages would easily transfer from the first language to the second language as their validity is strengthened from input. Cues that are not consistent across languages would not be as likely to transfer because the learner may have a competing set of cues decreasing cue validity (Kuppersmitt, 2004; Trevise \& Remy, 1986; Seliger, 1989). MacWhinney (2005) describes this transfer as a "syntactic accent" in the second language interpretation of sentences based on first language cues.

Transfer in the unified model is not unidirectional. Bilinguals may use different strategies in each language based on cue strength. Strategies of cue use includes forward transfer, which is the use of first language cues used in the second language; backward transfer, which is the use of second language cues used in the first language; differentiation, in which bilinguals demonstrate no transfer of cues from one language to the other; or amalgamation, which is a combination of first language and second language cues that are applied to both languages. The different use of transfer strategies for bilinguals provides evidence for the notion that bilinguals do not function with two independent language systems (Grosjean, 2001). For sequential bilinguals, the second language (lexicon, phonology, morphosyntax) is proposed to have a parasitic relationship with the first language structures until developed, but assumed to share the underlying cognition (MacWhinney, 1997). Competition can occur between the first language and the second language at the level of phonology, lexicon, and morphosyntax while the underlying cognitive structure is shared.

The unified model includes the cultural contexts of language use when considering cue strength (MacWhinney, 2005). Such an account predicts that if there is consistency in the cultural use of language for bilinguals, then we can expect transfer of pragmatic patterns of language use, or differentiation if the patterns are unique. Narration is a functional use of language that incorporates all of these aspects of 
language: pragmatics, grammar, and lexical knowledge. Their use will affect the way that a story is told. Input, linguistic structure, lexical knowledge and cultural experiences in both languages may bear on the way that bilinguals acquire and produce discourse in two languages. From a functional perspective, children's stories may differ in structure relative to the cultural exposure and linguistic structures used to relate the information. Within the context of culture, stories may vary as a function of input and exposure. However, across languages, similar patterns of development in storytelling should occur as cognitive and linguistic skills develop (Berman \& Slobin, 1994; Stromqvist \& Verhoeven, 2004).

\section{NARRATIVE SKILLS AND COGNITION}

Bruner (1986) writes of the human thought process as a narrative mode of thought. The stability seen in the patterns of producing and remembering story information across cultures and linguistic groups led Mandler, Scribner, Cole \& Deforest (1980) to suggest a cultural universal in the structure of folktales. According to Tomasello's view of cultural inheritance (1999), such a narrative structure is utilized as a cognitive tool for memory and utilized as a cultural inheritance when passed from generation to generation.

Stein and Glenn (1979) attributed narrative comprehension to an internal or cognitive memory structure for narratives, akin to an abstract knowledge structure referred to as schema (Bartlett, 1932). From an input perspective, a narrative schema is an abstraction of "story" resulting from repeated exposure to stories with common underlying structures (Kintsch, 1978; Mandler, 1983; Rumelhart, 1975). Mental representations of story are referred to as the story grammar (Bamberg, 1987; Brewer \& Dupree, 1983; Mandler \& Johnson, 1977; Rumelhart, 1975; Stein and Glenn, 1979; Thorndyke, 1977). Individual elements consist of a setting to introduce the characters, timeframe, and location elements. The plot structure of the story is contained in the prototypical episode or episodes consisting of an initiating event, which is frequently the 
problem the main character needs to solve. The problem needs resolution, after a reaction to the problem or internal response is realized, which causes an attempt or goal directed action solve the problem. The result is a consequence to the action, and a reaction to the consequence. Story grammars logically depict the episode structure of a story (Bamberg, 1987; Haberland, Berian \& Sanderson, 1980) and, like any schema, guide the listener in both encoding and retrieving the information and details of the story (Anderson, Reynolds, Schallert, \& Goetz, 1977; Bamberg, 1987; Duchan, 1986; Mandler, 1978).

As children develop narrative competence, it is impossible to deny the role that the adult plays in providing not only a story model but also the scaffolding for children to acquire this form of discourse. Research suggests that children's cognitive skills develop through early interactions with adults (Vygotsky, 1978), and that communication skills develop through these interactions (Bruner, 1985). Initially, parents begin to scaffold children's conversations about the past by providing both structure and content by initiating topics and scaffolding children's speech (Hudson, 1993). Scaffolding children's recounts of specific and special events by memory in sequence may help develop the underlying cognitive skills related to language use. European-American parents may stress concepts of sequencing by asking children to relate events by providing cues of temporal markers (Melzi, 2002). Later, adults may begin to ask memory questions that require the child to provide content (Eisenberg, 1985). When parents use prompts for children to include specific aspects and structures of narration, the prompts become internalized and children begin to spontaneously include these aspects (Fivush, 1991; Peterson \& McCabe, 1994). As such, the sociocultural contribution of learning to narrate is consistent with Vygotsky (1986). He proposed that when parents or more competent peers interact with children in the context of learning a new skill, cognitive processes such as attention and perception may be changed by the interaction, leading to higher independent functioning. 
Narrative production and comprehension tasks are a prominent part of the early elementary school years central to academic literacy goals (Cazden, 2001; Gillam, McFadden \& van Kleeck, 1995). Narrative skills are important precursors to literacy for monolinguals (Dickinson \& Tabors, 2001) and bilinguals (August \& Shanahan, 2006; Oller \& Pearson, 2002). Recent research suggests that narrative skills specifically story comprehension in English and Spanish are predictive of reading skills within and across languages for bilingual Spanish-English speaking childen in K-3 ${ }^{\text {rd }}$ grade (Lindsey, Manis \& Bailey, 2003; Manis, Lindsey \& Bailey, 2004; Miller, et al., 2006; Pollard-Durodola, Mathes, Vaughn, Cardenas-Hagan, \& Linan-Thompson, 2006; Proctor, Carlo, August \& Snow, 2005). Because of the important like to literacy, exposure to different narrative genres is likely to begin in the early elementary years.

Although interactions with more competent adults or peers influences further development, culture influences the route and the expectations for development (Rogoff, 1990). This influence is reflected in the development of children's narration style (Melzi, 2000; Minami \& McCabe, 1995; Wang \& Leichtman, 2000). For instance, Japanese and American mothers demonstrated different interactions with their children (Minami, 2002). Japanese mothers used more interactional markers and switched topics, which shortened children's utterances. These differences are attributed to a Japanese cultural preference for conciseness. On the other hand, American mothers elicited more utterances per topic. The children exhibited a narrative interaction embedded in the culture in which it takes place.

It is in a particular cultural context that a narrator and listener(s) negotiate meaning. For example, during sharing time, teachers may purposefully shape the narratives of children to highlight information that is considered important for learning, or discourage information that seems "egocentric" (Cazden, 2001). While narratives are used in particular contexts and are constructed within a cultural framework, there are language specific influences on narration. 


\section{NARRATIVE UNIVERSALS, DIFFERENCES, AND DEVELOPMENT}

Cross-linguistic research has documented similarities in the development of narratives. Studies have analyzed narratives elicited from Hebrew, English, Spanish, German, and Turkish children and adults using the same wordless picture book (Berman \& Slobin, 1994) and more recently the work has been expanded to include some indigenous languages and bilingual comparisons of languages in contact (Stromqvist \& Verhoeven, 2004). Notably, stories were identifiable by age group, showing parallel cross-linguistic development of narrative skill alongside cognitive development. Young children (3 years) generally described the pictures, and used action, object, and character names. By age 5, children included the story events, and at least a few plot elements. Unlike the younger children, the 5-year-olds demonstrated an awareness of temporality to express event sequence and more consistent tense markings. By age 9 children made explicit references to plot events, used consistent tense, causally linked events, and referenced internal states of the characters. Their narrative structure was organized and unified with complex syntax employed to elaborate on events. The adults used more lexically specific verbs such as discover, and complex syntax to "package" the events.

Parallel narrative development across languages is evidence that children may develop a global structure for story that is independent of language. Because Language is the vehicle used to tell a story, linguistic differences and language-specific rhetorical options will have a role in the way that a story is told. An example of cross-linguistic differences seen in narratives is evident in a comparison of the way that Spanish and English narrators encode verbs of motion (Berman \& Slobin, 1994). In English, a large number of locative particles were combined with verbs of motion to distinguish the trajectory of movement (e.g., "The owl flew out of the hole”). In contrast, Spanish verbs encode change of location (e.g., "Quería subir el perro [“Wanted to go up, the dog.”] p. 271). The comparisons in Berman and Slobin's (1994) work demonstrate that major differences in narrative structure were developmental as opposed to cross-linguistic, 
whereas the cross-linguistic differences were related to differences in linguistic forms. The narrators told essentially the same stories across languages, but got there by using the different linguistic options available in their language. Therefore, the language of story telling may influence the microstructure of a story whereas cultural influences may have a greater effect on narrative macrostructure.

Cross-linguistic data from Berman and Slobin (1994) and Stromqvist and Verhoeven (2004) demonstrates differences in linguistic style. Culturally contrasting parent-child dyads demonstrate differences in how children learn to interact with their listener. Further cross-cultural and cross-linguistic data demonstrate structural differences in narrative form, specifically differences highlighting goal-oriented behavior in Japanese and Native-American narratives (Matsuyama, 1983; Westby, et al., 2002). For instance, Matsuyama (1983) found that the story grammar models of Thorndyke (1977) and Mandler and Johnson (1977) did not adequately describe the story structure of Japanese folktales. For example, $80 \%$ of the stories did not have a goal structure for the main character, as suggested by Western story grammar. Typically, only the villain was goaloriented, and the main character(s) were not, perhaps explained by the culture being rooted in Buddhism which does not encourage goal-oriented behavior. Thus, the models of story grammar proposed that include a goal-structured sequence may not be universal.

These cross-cultural studies demonstrate the role of culture on narrative structure. Differences in models of narrative structure may influence children's organizational structure when producing stories. These models may not match up to the EuropeanAmerican story model. In sum, a view of narrative development that considers the role of culture in the use of narratives and the prominence of specific aspects of narratives is necessary to explain differences in narrative structure across cultural and linguistic group.

While children's developmental trajectories of narrative growth may look comparable across languages (Berman \& Slobin, 1994; Stromqvist \& Verhoeven, 2004), specifically the development of narrative organization and structure, the microstructural 
elements including linguistic structures and rhetorical forms may differ across languages. For monolingual English and Spanish speakers (Berman \& Slobin, 1994), contrastive differences between Spanish and English were noted in verb morphology and tense, encoding of temporal information, movement in space, reliance on relative clauses, and subject ellipsis. In other words, while children's global narrative structure appeared similar across languages with respect to age, and children's command of their respective languages increased with respect to age, children's use of linguistic forms to carry out specific narrative functions varied with respect to the language-specific options available to produce their story.

\section{DIFFERENTIAL PROFILES OF BILINGUAL NARRATIVES}

The relationship between language, culture, and thought has been a topic of study for decades. The Sapir-Whorf Hypothesis (Whorf, 1956) proposes that the language we speak shapes our thought process and the way we interpret the world around us. Studies of bilingual's narrative productions indicate that the language of production has an effect on how a story is told and what information is highlighted (Bedore, Fiestas, Peña \& Nagy, 2006; Fiestas, Peña, Gorman \& Gillam, 2003; Fiestas \& Peña, 2004; Marian \& Kaushanskaya, 2004; Kuppersmitt, 2004; Silliman, Bahr, Brea \& Hnath-Chisolm, and Mahecha 2002; Soter, 1988; Stavans, 2003; Tannen, 1980; Westby, Moore \& Roman, 2002). Observation of these studies through the lens of the unified model highlights the complex interaction of language, cognition, and culture. The differential narrative profiles for bilinguals may be explained by different strategy use based on cue strength, resulting in stories with a unique linguistic or cultural narrative footprint. From a functional perspective, an individual using two languages must make on-line decisions based on cues from language form, content, and use while narrating a story. For instance, Westby and colleagues (2002) found cultural differences in written narratives produced in English by bilingual Native American Keres and English-speaking children as compared to children's narratives from the mainstream culture. Native American 
narrators rarely included character's emotions, thoughts and intentions, and characters in the children's stories rarely achieved goals through their own actions, but instead by a force out of their control. The authors attribute these findings to observations of Keresan speakers who rarely use indirect speech or discuss the thoughts and feelings of others in narrative.

Similarly, in a comparison of stories told in Russian and English by bilinguals, Marian and Kaushanskaya (2004) found that the language of production had cultural ties to identity and emotion. Russian-English bilinguals expressed more emotion when the language of production matched the language of an event. Further, the cognitive style of narration matched the cultural identity of the language. Stories in English were individualistic while Russian stories were collectivist.

With respect to microstructure, contrastive linguistic differences in children's stories were found when studying stories produced by Spanish-speaking bilinguals learning Hebrew (Kupersmitt, 2004). When narrating the same story in Spanish, bilingual children's grammatical structures were unlike those of monolingual Spanish speakers, indicating an amalgamation of linguistic cues from both languages. For instance, children used connectors that were unusual in Spanish, but reflected translations of more common Hebrew connectors (e.g. "In the meanwhile ["Mientras tanto"]) which is used in Hebrew to discuss co-occurring events. Additionally, in Spanish the bilingual children used fewer instances of past perfective than monolingual Spanish speakers the same age. Past perfective is marked in Spanish, but not in Hebrew. Results demonstrate the effect of Hebrew linguistic forms and rhetorical options on children's Spanish narrative productions.

While these studies demonstrate language-specific differentiation and the amalgamation of cues in bilinguals, evidence also exists for transfer at the level of story organization (Silliman, et al., 2002; Soter, 1988; Stavans, 2003; Westby, et al., 2002). In a study comparing monolingual Americans and Israelis to adult bilingual Americans 
(English was the first language, Hebrew the second language) and Israelis (Hebrew was the first language, English the second language), Stavans (2003) found evidence of transfer when the bilinguals related narratives in English or Hebrew. As a reference, monolingual's Hebrew stories were "top heavy" with time dedicated to the initiation of a problem. The monolingual's English stories were "bottom heavy", dedicating more propositions to the solution of the problem. Macrostructural differences were transferred that were akin to the culture (American and Israeli) of the language of production for bilingual English and Hebrew speakers. The Israeli bilinguals used a top-heavy organization when relating the stories in both English (the second language) and Hebrew (the first language), demonstrating forward transfer (the first language Hebrew to the second language English) of story organization. American bilinguals produced "bottom heavy" stories emphasizing the solution component in both Hebrew (the second language) and English (the first language), consistent with first language macrostructure. Both bilingual groups demonstrated transfer of their first language patterns of narrative organization to the second language.

Of interest to the present study, there has been research examining the narratives produced in both languages by bilingual Latino Spanish and English-speaking bilingual children. With respect to macrostructure, Fiestas and Peña (2004) found that bilingual children telling the same story used more attempts and initiating events in Spanish, while producing more consequences in English. Thus, children were using organizational schemata that could have cultural ties to each language. These results are consistent with previous findings of differences between what is emphasized in the narratives of Spanish and English speakers (Rodino, Gimbert, Perez, Craddock-Willis \& McCabe 1991; McCabe, 1997; McCabe \& Bliss, 2003; Silliman et al., 2002; Silva \& McCabe, 1996). The narratives of Spanish speaking children favored description, location, psychological states, and the evaluation of experiences, and often included details about connection between experiences and family and friends as compared to going into detail about 
objects or events. From a clinical perspective, these differences have implications for bilinguals, and how the language of testing could influence performance.

Research on the narrative development of bilingual children is limited for speakers of Spanish and English. However, there are a few studies documenting some general trends in development for bilingual children. Studies of age-related effects on narration have taken development and language use into account. Muñoz, Gillam, Peña and Gulley-Faehnle (2003) documented age-related increases in sentence length, grammatically acceptable utterances, and story structure (incomplete and complete episodes) in the English narratives of Latino preschool children, providing evidence for development in the second language for these English-language learners.

Further studies document the age-related development of narrative skills in both languages with differences likely attributed to academic exposure to English. Uccelli and Paez's (2007) study of K- $1^{\text {st }}$ grade bilinguals found gains in microstructure for total number of different words (TNDW) proving to be a sensitive developmental measure. In Spanish, children made significant gains only on macrostructure (e.g. narrative story score). Pearson's Miami study (2002) of $2^{\text {nd }}$ and $5^{\text {th }}$ graders provided evidence of crosslanguage correlations for story structure and sentence complexity, which provides evidence for general development of narrative skills in both languages. In a large study of 1500 bilingual children from Kindergarten to $3^{\text {rd }}$ grade, Miller et al. (2006) found significant increases in microstrure (utterance length, and number of different words) and macrostructure (narrative score comprised of story grammar measures, specific referencing, mental state verbs, and coherence). Significant positive trends were seen for both languages across grades. The only trend towards a language difference was higher Spanish narrative scores until $3^{\text {rd }}$ grade, when there is likely increased academic exposure to English. The higher Spanish narrative scores may relate to better proficiency in Spanish until that time. This is consistent with findings of Fiestas et al. (2003). First graders in Spanish included more "attempt" story-grammar propositions and more 
complex goal planning, macrostuctural elements, and more different words than English, while children told stories of the same length, included equal numbers of internal responses and cognitive states regardless of language and proficiency group. Thus, bilingual children may present differential profiles of performance according to the language of testing in a cognitively and linguistically demanding task such as storytelling.

\section{NARRATIVE PRODUCTION IN CHILDREN WITH LI}

Narrative assessment is used to differentiate children with language learning problems from typically developing children for assessment purposes (Boudreau, 2008; Culatta, Page \& Ellis, 1983; Griffith, Ripich \& Dastoli, 1986; Liles, 1993; McFadden \& Gillam, 1996; Newman \& McGregor, 2006; McGillivray, \& Schmidek, 1997). From narrative assessment, speech-language pathologists may obtain information regarding developmental measures of language skills. Specific aspects of language include mean length of utterance (MLU), (Brown, 1973; Miller \& Chapman, 1981), linguistic uncertainty or maze use (Loban, 1976), and grammatical markers typical of LI such as deficits in grammatical complexity and accuracy. Additional aspects of language examined in narratives include: narrative microstructure, including measure of lexical diversity and productivity (Justice, et al., 2006), and narrative macrostructure, such as story grammar adapted from (Stein \& Glen, 1979), which uses a propositional approach to describe the macrostructure of the stories that children tell (Ripich \& Griffith, 1988; Merritt \& Liles, 1987; Perez \& Tager-Flussberg, 1998; Hughes, McGillivray and Schmidek, 1997). Additionally, information about fluency (Guo, Tomblin \& Samelson, 2008; Riggenbach, 1991) and pragmatic skills (Botting, 2002) may be obtained from a narrative sample.

Children with language impairment frequently exhibit deficiencies in narration, and these problems may have profound academic and social implications (Gillam, et al., 1995). Specifically, the narratives of children with LI are less cohesive, include fewer 
story grammar elements, include less causal connectivity, and are less organized in their episode structure than the narratives of typically developing children (Gillam \& Carlile, 1997; Hayward, Gillam, \& Lien, 2007; Liles, 1985a, 1985b, 1993; Merrit \& Liles, 1987; Norbury \& Bishop, 2003). Narrative deficits of children with LI may be in part impacted by sentence level grammatical errors, a smaller vocabulary and reduced syntactic complexity that are the hallmarks of language impairment. The interaction of sentence structures and content organization is accounted for in a model of discourse proposed by Kintsch and van Dijk (1978) and van Dijk and Kintsch (1983). In this model, an interaction of cognitive strategies governing global or macrostructure (discourse structure and content) and local aspects or microstructure (linguistic structures) guide the production and comprehension of textual-level discourse. Children with LI demonstrate difficulties with global or/or local aspects of narration, thus producing narratives that are less than adequate. For bilingual children, these deficits would be present in both languages.

Research on the narratives of bilingual children with LI is sparse, but suggests that performance in each of the two languages would be consistent with the deficits seen in the narratives of monolingual children with language impairment. Spanish-speaking children with LI retelling stories demonstrated difficulties similar to English monolingual children with LI (Gutierrez-Clellen, 2004). Problems included difficulties relating main events and limited story recall. We might predict for bilinguals, as with monolinguals, difficulties at the global level, which could include problems with organization of narrative structure and cohesion. Difficulties at the local level would include problems with microstructure, specific grammatical structures, lexical diversity, sentence complexity and language specific aspects which cross-linguistic research has shown to be problematic. Examples include clitic or gender marking in Spanish or past-tense marking in English (Bedore, 2004). 
From a practical standpoint, an examination of the influences of the language of intervention during the intervention portion of DA on performance in both languages has implications for interpreting assessment results as well as decisions about the language of intervention. From a theoretical perspective regarding language input, of particular interest is whether the language of intervention influences change in the untrained language.

Optimally, intervention for children with language impairment should meet the specific language needs of the child. For bilingual children, the language of intervention has been a subject of uncertainty, and data to guide clinical decisions have been scant. Currently, two opposing positions guide intervention choices for LI children learning English as a second language (Kayser, 1995; Gutierrez-Clellen, 1999). One position is that intervention in the "native" or first language is instrumental for developing language skills in both the first language and the second language (Kiernan \& Swisher, 1990; Perozzi, 1985; Perozzi \& Chavez-Sanchez, 1992; Thordardottir, Weismer, \& Smith, 1997). According to this position, the skills learned in the first language would transfer to the second language, and success in the second language may be predicted by the acquisition of these skills in the first language (Cummins, 1991). The second position relates to the "time-on-task" principle. That is, intervention in the second language is assumed to provide more practice and needed time for the acquisition of the second language (Barclay, 1983; Porter, 1996). The "time-on-task" position may be based on an assumption that bilingualism is not easily accessible for children with LI (Ortiz \& Garcia, 1990). Children's language knowledge reflects the languages that they are exposed to (Pearson \& Fernandez, 1994). Many professionals are wary of providing input in both languages believing this could exacerbate the problem of language acquisition (Toppelburg, Snow, \& Tager-Flusberg, 1999). Frequently, parents of bilingual children with LI may be advised to eliminate one language to maximize learning of the other 
language (Juarez, 1983; Kayser, 1995), or advised that support should be provided in the language used in the school.

More recently, researchers propose that bilingual intervention should be used to support bilinguals with LI (Gutierrez-Clellen, 1999; Kohnert \& Derr, 2004; Thordardottir, Weismer, \& Smith, 1997; Peña \& Kester, 2004) yet there are limited group investigations of the specific effects of first language and second language intervention on functional measures of language use in children with LI. Current studies of the language of intervention have been single case studies (Thordardottir, Weismer, \& Smith, 1997), or studies have focused mostly on single domains of language learning such as vocabulary acquisition (Kiernan \& Swisher, 1990; Perozzi, 1985, Perozzi \& ChavezSanchez, 1992). As such, language of intervention studies have not yet focused on more functional uses of language such as narration.

Determination of the optimal language(s) for intervention requires understanding of interactions between the first language and second language for language input and language use, and the factors which may influence knowledge specific to each language (Grosjean, 1997). Language intervention serves to provide support for the acquisition of language when a child's language system is not interacting effectively with input to learn language. Of interest is extending the DA of narratives to a bilingual population to examine questions pertaining to the feasibility of such an application using the same stimuli as used in the monolingual population, and the use of a short-term intervention to investigate the language of input, transfer, and the language of production for both typically developing and language-impaired bilingual children.

\section{QUESTIONS OF THE CURRENT STUDY}

For the present investigation, we will we will conduct three interrelated studies applying the DA paradigm to bilinguals to answer the following questions:

\section{Study one}

1. Do the two stories TF and BR elicit parallel stories within languages? 


\section{Study two}

1. Does the language of story production (Spanish or English) affect measures of narrative skill for bilingual children?

2. Is there a difference in the improvement of narrative skills due to the language of mediation (Spanish or English) for Spanish and English-speaking bilingual children?

3. Do aspects of narrative language targeted during mediation transfer to the nontargeted language for TD and LI children, and if so, which aspects transfer to which language?

4. Are there language specific gains (Spanish or English) relative to the language of intervention (Spanish or English) for bilingual children with and without LI?

\section{Study three}

1. Are there differences in pretest to posttest change in children's stories following mediation for children who are developing language typically and children with LI as compared to a control group, and if so, what are the patterns of differences?

2. Are there differences in modifiability scores for LI and TD children and are there any differences in modifiability due to the language of mediation? 


\section{Chapter 2: Methods}

\section{PARTICIPANTS}

A sample of 98 bilingual children between the ages of $6 ; 3$ and $9 ; 2(M=$ 7;5) in first- and second-grade from elementary schools in Central Texas participated in the three studies. The children were sequential bilinguals who learned Spanish in the home and had formal exposure to English upon entering preschool or elementary school. All children had at least 20\% exposure to Spanish and English to qualify as bilingual. Fifty-eight of the children had typically developing language, and they were assigned to receive intervention or to a control group. Nineteen of the typical language children served as control subjects, and 49 were assigned to participate in the intervention. An additional 30 children were determined to have a language impairment (LI). In addition to the 98 children, two children did not qualify to participate. One child had a positive history of head trauma and one child moved after the pretest portion of the study. See Table 1 for gender, grade, age, and language use information for the groups. All of the children were recruited from public school districts in Central Texas with bilingual programs that enroll large numbers of Latino students.

Permission slips were given to students in first and second-grade bilingual classrooms in five schools in two districts in Central Texas. Permission slips were also given to speech-language therapists in the schools in order to identify children with LI for the study. Parents gave permission for children to participate in the study, and for data to be obtained from teacher and parent questionnaires and a review of school records.

Parent and teacher questionnaires were used to determine language proficiency, exposure and use (Gutierrez-Clellen \& Kreiter, 2003), and prior history of speech and language services. Parent interviews were conducted over the phone or face-to-face for several children whose families did not have phones. Parents were interviewed about their children's language abilities and language history. Parents rated their children's 
proficiency in both languages on a 4-point scale and were asked if they had any concerns about their children's language or speech. Language history was documented according to what languages the child had been exposed to during development. Language input and use were documented for the hours of the day that children were awake on weekdays and weekends. Children were classified as bilingual if they had $20 \%$ or greater home and school input in both Spanish and English consistent with previous work (Bedore, Fiestas, Peña \& Nagy, et al, 2006; Fiestas \& Peña, 2004; Gutierrez-Clellen, 2002; GutierrezClellen \& Kreiter, 2003; Pearson, Fernandez, Lewedeg \& Oller, 1997). As with the parent interviews, teacher questionnaires were used to document exposure, use, and proficiency of both languages in the classroom and to document any concerns about the child's language abilities. The children were early sequential bilinguals who had learned Spanish at home and formal English starting with school and preschool exposure.

\section{Table 1}

Group descriptions

\begin{tabular}{lclllllll}
\hline Group & $\mathbf{N}$ & $\begin{array}{l}\text { Mean } \\
\text { Age in } \\
\text { months } \\
(\text { SD) }\end{array}$ & $\begin{array}{l}\text { Grade } \\
\text { 1 }\end{array}$ & $\mathbf{2}$ & $\begin{array}{l}\text { Sex } \\
\text { M }\end{array}$ & $\mathbf{F}$ & $\begin{array}{l}\text { Output } \\
\text { Spanish (SD) }\end{array}$ & $\begin{array}{l}\text { Output } \\
\text { English (SD) }\end{array}$ \\
\hline Control & 19 & $88(7.6)$ & 9 & 10 & 12 & 7 & $62.0 \%(14.7)$ & $38.0 \%(14.7)$ \\
TD & 49 & $90(9.7)$ & 20 & 29 & 21 & 28 & $61.5 \%(15.3)$ & $38.5 \%(15.3)$ \\
LI & 30 & $87(10.3)$ & 22 & 8 & 13 & 17 & $59.9 \%(20.1)$ & $40.1 \%(20.1)$ \\
\hline
\end{tabular}

\section{Subjects with typical language development}

Children in the typically developing and control groups met the following criteria:

(1) teachers demonstrated no concerns regarding children's expressive or receptive language or speech via teacher questionnaire; (2) parents indicated no concern about their children's receptive or expressive language or speech as documented in the parent questionnaire; (3) children had cognitive skills in the normal range as measured by a 
standard score between $75-125$ on the symbolic memory and cube design screening subtests of the Universal Nonverbal Intelligence Test (UNIT, Bracken \& McCallum, 1998); (4) children scored within one standard deviation of the group mean for their age in their better language on the semantics and syntax subtests in Spanish or English of the Bilingual English-Spanish Assessment battery (BESA; Peña, Gutierrez-Clellen, Iglesias, Goldstein, \& Bedore, in preparation). This language test, which measures both receptive and expressive language, was chosen because a significant percentage of the standardization sampling was taken from bilingual children in Central Texas. See Table 2 for descriptive data for language and cognitive testing.

Table 2

Group language raw scores and cognitive test standard score

\begin{tabular}{llllll}
\hline Group & $\begin{array}{l}\text { English } \\
\text { semantics } \\
(\text { SD) }\end{array}$ & $\begin{array}{l}\text { Spanish } \\
\text { semantics } \\
(\boldsymbol{S D})\end{array}$ & $\begin{array}{l}\text { English } \\
\text { Syntax } \\
(\boldsymbol{S D})\end{array}$ & $\begin{array}{l}\text { Spanish } \\
\text { syntax } \\
(\boldsymbol{S D})\end{array}$ & $\begin{array}{l}\text { Cognitive } \\
\text { Std. score } \\
\text { (SD) }\end{array}$ \\
\hline Control & $34.2(7.4)$ & $38.9(3.3)$ & $83.2(19.9)$ & $94.0(7.6)$ & $103(13.7)$ \\
TD & $33.7(8.0)$ & $38.6(3.9)$ & $81.7(22.1)$ & $90.5(11.3)$ & $95.5(17.3)$ \\
\hline LI & $25.3(7.5)$ & $26.4(7.8)$ & $52.7(25.8)$ & $57.3(22.8)$ & $92.7(12.7)$ \\
\hline
\end{tabular}

\section{Subjects with language impairment}

Children were identified as LI if they met one of the following two criteria: (1) identification as language-impaired by a certified bilingual speech-language pathologist with graduate level training in bilingual assessment practices; or (2) parent and/or teacher concern about language status. Additionally, children identified as LI also scored $<1.25$ S.D. below preliminary age norms for the syntax and/or semantics subtest of the BESA (Peña, et al., in preparation) in both languages. In order to ensure that poor language skills could not be attributed to low cognitive skills, children's cognitive skills were examined and were in the normal range (SS between 75-125) as determined by performance on the symbolic memory and cube design screening subtests of the Universal Nonverbal Intelligence Test (UNIT, Bracken \& McCallum, 1998). 


\section{Group assignment}

Children in the TD group were randomly assigned within grade to one of three conditions: Control, Spanish mediation, or English mediation. Children in the Control group did not receive mediation. Participants in the LI group were randomly assigned to the Spanish or English mediation group. Within each group children were then randomly assigned to cohort A or B, which designated the order of languages to be used for pretesting (Spanish or English) and the book used for elicitation TF or BR (Two Friends; Miller, 2000b or Bird and His Ring; Miller, 2000a). Refer to Table 3.

Table 3

Research design

\begin{tabular}{|c|c|c|c|c|c|c|}
\hline Group & Total N & Cohort & $\begin{array}{c}\text { Cohort } \\
n\end{array}$ & $\begin{array}{c}\text { Order of } \\
\text { testing: Pretest }\end{array}$ & $\begin{array}{c}\text { Language of } \\
\text { MLE }\end{array}$ & $\begin{array}{l}\text { Order of } \\
\text { testing: } \\
\text { Posttest }\end{array}$ \\
\hline \multirow[t]{4}{*}{ Control } & \multirow[t]{4}{*}{19} & \multirow[t]{2}{*}{ A } & \multirow[t]{2}{*}{9} & TF Spanish & \multirow[t]{2}{*}{ NA } & TF English \\
\hline & & & & BR English & & BR Spanish \\
\hline & & \multirow[t]{2}{*}{ B } & \multirow[t]{2}{*}{10} & TF English & \multirow[t]{2}{*}{ NA } & TF Spanish \\
\hline & & & & BR Spanish & & BR English \\
\hline \multirow[t]{8}{*}{$\mathrm{TD}$} & \multirow[t]{8}{*}{49} & \multirow[t]{2}{*}{ A } & \multirow[t]{2}{*}{11} & TF Spanish & \multirow[t]{2}{*}{ Spanish } & TF English \\
\hline & & & & BR English & & BR Spanish \\
\hline & & \multirow[t]{2}{*}{ B } & \multirow[t]{2}{*}{14} & TF English & \multirow[t]{2}{*}{ Spanish } & TF Spanish \\
\hline & & & & BR Spanish & & BR English \\
\hline & & \multirow[t]{2}{*}{ A } & \multirow[t]{2}{*}{12} & TF Spanish & \multirow[t]{2}{*}{ English } & TF English \\
\hline & & & & BR English & & BR Spanish \\
\hline & & \multirow[t]{2}{*}{ B } & \multirow[t]{2}{*}{12} & TF English & \multirow[t]{2}{*}{ English } & TF Spanish \\
\hline & & & & BR Spanish & & BR English \\
\hline \multirow[t]{8}{*}{ LI } & \multirow[t]{8}{*}{30} & \multirow[t]{2}{*}{ A } & \multirow[t]{2}{*}{7} & TF Spanish & \multirow[t]{2}{*}{ Spanish } & TF English \\
\hline & & & & BR English & & BR Spanish \\
\hline & & \multirow[t]{2}{*}{ B } & \multirow[t]{2}{*}{7} & TF English & \multirow[t]{2}{*}{ Spanish } & TF Spanish \\
\hline & & & & BR Spanish & & BR English \\
\hline & & \multirow[t]{2}{*}{ A } & \multirow[t]{2}{*}{7} & TF Spanish & \multirow[t]{2}{*}{ English } & TF English \\
\hline & & & & BR English & & BR Spanish \\
\hline & & \multirow[t]{2}{*}{ B } & \multirow[t]{2}{*}{9} & TF English & English & TF Spanish \\
\hline & & & & BR Spanish & & BR English \\
\hline
\end{tabular}




\section{PRocedures}

\section{Dynamic Assessment}

Narrative Pre-test. All participants were pretested in both Spanish and English by producing a story in each language using two wordless picture books (one for each language) for elicitation. Both stories involve a similar search and find theme. Children looked at all of the pictures in the story, and then were instructed to tell a story to go along with the pictures. Children told the stories while looking at the pictures page-bypage akin to Berman and Slobin's protocol (1994). All stories were audiotaped using a Marantz audio recorder and lavalier microphone.

The stories used to elicit narratives were Two Friends (TF) and Bird and His Ring (BR) developed for the dynamic assessment and intervention of children's narratives (Miller, et al., 2001). The two books are balanced for episode structure, length and story line (a search theme) with equal number of attempts depicted for the same number of characters. The books elicit parallel stories as compared by narrative and productivity measures from CLD monolingual children (Peña, et al., 2006). Only one language was used per session of testing. An additional story was collected at pretest in the language chosen for mediation using the wordless picture book Frog Where Are You (Mercer, 1969) in order to provide feedback data and narrative practice for use in the first MLE session.

Mediated Learning Experiences. All participants except the control group participated in two sessions, each 30 minutes, of a mediated learning experience (MLE) one-on-one with a clinician (see Table 3). Children were randomly assigned within ability group to receive MLE in either Spanish or English. Clinicians did not switch languages during the session, but used examples, contextual support and short sentences if limited language proficiency appeared to be a factor. The focus was to ensure that the child understood the goals set forth for the MLE session, thus it was the role of the 
clinician to supply comprehensible input based on principles of second language instruction (Krashen, 1985).

The goal of the MLE sessions was for the children to tell more complete stories than at pretest by improvements in episode structure, important detail, cohesion, length and complexity of the stories (see Table 4 for a description of both story components and episode structure). Scripts were used which included the essential components of

Table 4

Narrative items (adapted from Miller, et al., 2001)

\begin{tabular}{|c|c|c|}
\hline Measure & Scale & Description \\
\hline \multicolumn{3}{|l|}{$\begin{array}{l}\text { Story components } \\
4 \text { subscales }\end{array}$} \\
\hline Setting & 1 to 5 & Refers to where and when story takes place \\
\hline Character information & 1 to 6 & A description of the characters \\
\hline Temporal order of events & 1 to 5 & Words to depict the order sequence of action \\
\hline Causal relationships & 1 to 5 & $\begin{array}{l}\text { Information/explanation about why events occur; } \\
\text { causal connection }\end{array}$ \\
\hline \multicolumn{3}{|l|}{$\begin{array}{c}\text { Story ideas and language } \\
5 \text { subscales }\end{array}$} \\
\hline Complexity of ideas & 1 to 5 & $\begin{array}{l}\text { The cohesion of concepts; ideas ranging from } \\
\text { literal to abstract }\end{array}$ \\
\hline Complexity of vocabulary & 1 to 5 & The variation of words to express nuances \\
\hline Grammatical complexity & 1 to 5 & Variation and complexity of sentence structure \\
\hline Knowledge of dialogue & 1 to 5 & $\begin{array}{l}\text { Verbal interactions between characters; dialogue } \\
\text { use }\end{array}$ \\
\hline Creativity & 1 to 5 & How interesting and captivating is the story \\
\hline \multicolumn{3}{|l|}{$\begin{array}{l}\text { Episode structure } \\
1 \text { scale }\end{array}$} \\
\hline $\begin{array}{l}\text { None, incomplete to basic } \\
\text { episode }\end{array}$ & 1 to 3 & $\begin{array}{l}\text { Basic episode: includes an initiating event, } \\
\text { one or more attempts and consequence }\end{array}$ \\
\hline Basic episode + one, two & 4 to 5 & $\begin{array}{l}\text { A basic episode plus an internal response } \\
\text { and/or plan and/or a reaction }\end{array}$ \\
\hline Complete episode & 6 & All above elements present \\
\hline Multiple episode & 7 & $\begin{array}{l}\text { A combination of two or more complete or basic } \\
\text { episodes }\end{array}$ \\
\hline \multicolumn{3}{|l|}{$\begin{array}{c}\text { Story grammar } \\
\text { components making up } \\
\text { episode structure }\end{array}$} \\
\hline Initiating event (IE) & - & What propels the main character into action \\
\hline Internal response (IR) & - & $\begin{array}{l}\text { The main character's reactions or feelings about } \\
\text { the IE }\end{array}$ \\
\hline
\end{tabular}




\begin{tabular}{|c|l|l|}
\hline Attempt (A) & \multicolumn{1}{|c|}{-} & $\begin{array}{l}\text { The main character's attempts to achieve the } \\
\text { goal, } \\
\text { in response to the IE. }\end{array}$ \\
\hline Plan (P) & - & What main character(s) intends to do and why. \\
\hline Consequence (C) & - & The resolution of the IE \\
\hline Reaction/ending (RE) & - & $\begin{array}{l}\text { The main character's response to the C, } \\
\text { or some kind of ending. }\end{array}$ \\
\hline $\begin{array}{c}\text { Total score } \\
\text { 1 scale }\end{array}$ & 10 to 53 & $\begin{array}{l}\text { Provides a total score for story components, } \\
\text { story ideas } \\
\text { and language, and episode structure }\end{array}$ \\
\hline $\begin{array}{c}\text { Plan score } \\
\text { 1 scale }\end{array}$ & 0 to 6 & \\
\hline Plan 0 & 0 & No planning, descriptions of the pictures. \\
\hline Plan 1 & 1 & Labels an attempt as an isolated description. \\
\hline Plan 2 & 2 & $\begin{array}{l}\text { Attempt follows an internal response, } \\
\text { no relation to why or what. Goal is not stated }\end{array}$ \\
\hline Plan 3 & 3 & $\begin{array}{l}\text { Attempt explained, but not in terms of the } \\
\text { ultimate goal. }\end{array}$ \\
\hline Plan 4 & 4 & $\begin{array}{l}\text { Multiple attempts, but the ultimate plan isn't } \\
\text { revealed. }\end{array}$ \\
\hline Plan 5 & 5 & $\begin{array}{l}\text { The ultimate plan is revealed, } \\
\text { attempts drift from the overall plan. }\end{array}$ \\
\hline Plan 6 & 6 & The ultimate plan stated, attempts relate to goal. \\
\hline
\end{tabular}

mediation (intention to teach, meaning, transcendence, planning and transfer). The scripts which had been previously used with monolingual children in English (Peña et al, 2006) were translated into Spanish. The script was developed to standardize the MLE sessions, ensuring that all components were targeted, yet allow the clinician to respond to each child's responses when learning to include the target items in their stories. Across each session the focus was to help children improve their use of cognitive strategies (e.g., attention, comparison, problem solving, predicting, inferencing, and discrimination) with the ultimate goal of telling more organized and complete stories. For a detailed description of the MLE session, see Peña et al., (2006) and the scripts included in the Appendix A and B.

The MLE facilitators were graduate-clinician speech-language pathologists trained to conduct the MLE sessions via script practice, observation of three sessions, and observation and feedback of ongoing sessions by the trainer, a certified Speech-Language 
Pathologist. The children received the MLE sessions from a clinician who was blind to the child's language ability (LI or TD). For the first MLE session, the clinician played back the audiotape from Frog, Where are You?_(Mercer, 1969). Feedback from the initial story was employed to teach narrative story components and episode structure. The second MLE session was structured as the first, using the script to cover the content of the MLE session. A different wordless picture book with a search theme, One Frog Too Many (Mercer \& Mayer, 1975), was used to follow up teaching the story components and episode structure.

Both sessions of MLE were designed to teach the importance of including the story components and the episode structures. The purpose and importance of telling complete stories in real life were linked to the specific teaching goal of telling complete stories. Examples were used to relate the storytelling goal to the child's home and school experiences. The clinician assisted the child to include the story components and episode structure elements. Finally, the clinician discussed any differences seen in the children's stories during the session, and strategies were reviewed to aid the child in remembering to apply what was learned. Both of the MLE sessions were videotaped using a Sony Hi-8 recorder for each child in order to monitor treatment fidelity. Directly following each session, the clinician rated their impressions of the child's modifiability on the Mediated Learning Observation instrument (see Appendix C for a copy of the instrument).

Control subjects. Nineteen of the typically-developing bilingual subjects did not receive the MLE. The Control group was used to control for the practice effects of telling the stories for pre and post-testing in both languages, and as a comparison group to examine the effects of mediation. Children in the control group participated in their routinely scheduled classroom activities and instruction.

Narrative Post-test. All participants were post-tested in both Spanish and English by producing a story in each language using the books in counterbalanced order using the same protocol as for the pretest. For example if the child told Two Friends in English 
(TF) for pre-test, Bird and His Ring (BR) (Miller, 1999) was used to elicit the English post-test to avoid language-specific practice effects. See the research design (Table 3) which describes the order and counterbalancing of the narrative pre and post-testing and language of intervention. To limit examiner bias, post-test stories were told to a new examiner and collected between 4 to 6 weeks from the pretest. Posttest stories were recorded on audiotape as in the pretesting phase.

\section{Transcription}

Both pre and post-test narrative samples were transcribed in English or Spanish using Systematic Analysis of Language Transcription (SALT) (Miller \& Chapman, 2002; Miller \& Iglesias, 2003-2004). Each transcriber received about 10 hours of instruction and practice in transcription protocols. All samples were segmented into C-Units (Loban, 1976) consisting of a main clause and any subordinating clauses. Spanish segmentation differed slightly in that when subject ellipsis occurred from a second main clause (el perro corrió y buscó al gato/ the dog ran and looked for the cat) the two clauses were segmented into two separate C-Units based on Miller et al. (2006).

A second transcriber reviewed the transcript while listening to the audiotape and corrected any transcription errors that they encountered. A third round of review was performed to ensure that all transcripts were compatible with the SALT software. SALTgenerated analyses of productivity including total number of utterances, total number of words, total number of different words, and mean length of C-unit in words (MLU-W) were entered into a spreadsheet for further analysis.

\section{Narrative item scoring}

In addition to the productivity measures, the pretest and posttest transcripts were scored for the following components of narration (based on Miller, Gillam, \& Peña, 2001; Peña et al., 2006). See Table 4 for an overview of narrative measures. Composite scores include: story components, story ideas and language and episode structure. Total 
scores are made up of the composite scores ranging from 10 to 53. The plan score is a scaled measure of children's overt statements of a plan to solve the problem encountered by the main characters in the story. This measure, developed by Fiestas et al. (2003) was found to be sensitive to language proficiency for bilingual children. A description of the plan scoring rubric is also presented in Table 4.

\section{Modifiability}

Following each mediation session, clinicians rated their impressions of the child's modifiability using the Mediated Learning Observation (MLO; Peña \& Villarreal, 2000). The two main sections of the instrument consist of internal and external social-emotional behavior and also the cognitive features of arousal and elaboration (Peña, et al., 2007). The 12 items are rated using a 5-point scale, with the highest score demonstrating need for a high degree of mediator support and low score indicating ability to use the strategy independently (see Appendix C). Scores can range from 12 to 60, with a high score overall indicating a lot of examiner support during MLE, and low scorers needing minimal support. Peña, et al. (2007) indicate that the cognitive arousal and elaboration subscores, specifically flexibility and metacognition, differentiated the LI and TD groups with a high degree of accuracy using the dynamic assessment methodology.

\section{Reliability}

Transcription reliability was calculated on a random sample of pre and posttest transcripts to for a total of 20 English and 20 Spanish transcripts. The samples were transcribed by a separate rater. The Intraclass Correlation Coefficient (ICC) was calculated for interrater reliability of two independent raters for Spanish and English including number of C-units, (Spanish = .939, English = .965), MLU-W (Spanish = .916, English $=.962)$, number of clauses (Spanish $=.960$, English $=.991$ ), number of different words $($ Spanish $=.960$, English $=.991)$, number of total words $($ Spanish $=.925$, English $=.993)$, and number of clauses $($ Spanish $=.995$, English $=.982)$. 
Reliability for the narrative scores was calculated by random selection of 24 stories in Spanish and English by two independent raters. The ICC was calculated for reliability in Spanish and English. Reliability for the English stories $=.957$, and for the Spanish stories $=.891$.

\section{Fidelity of treatment}

The fidelity of the MLE sessions was calculated by randomly selecting 10 videotapes of the sessions to rate the consistency and quality of the intervention. Consistent with Peña et al. (2001; 2006), the Mediated Learning Experience Rating Scale (Lidz, 1991) was the instrument chosen to document treatment fidelity. The scale includes the four components of mediation (intentionality, transcendence, meaning, and competence) and a 4 point rating scale from 0-3 for the inclusion of the components for a total possible score of 12. A score of 0 indicated no evidence of inclusion, a rating of 1 meant that the component was present but unelaborated, a rating of 2 indicated consistency in the use of the component while providing elaborations and a rating of 3 demonstrated the highest level of mediation where a general rule was provided. The mean rating for the MLE sessions was 10.17, indicating that the clinicians consistently included the target components and often elaborated them indicating that the sessions were at the two highest levels of mediation.

\section{Analyses}

Parallel forms of the two stories across languages, the effects of language of production, intervention, the transfer of skills across languages, and the patterns of differences across language ability groups were analyzed. Examination of the various aspects of narration allowed analysis of how children integrate macrostructural and microstructural elements simultaneously. These global and local aspects of language form and content were the dependent measures. Specifically, the macrostructural aspects were the organizational story grammar, ideas, cohesive and stylistic elements children 
chose to tell a story. The narrative measures analyzed (see Table 4 for an overview) included the total score, three category scores that make up total score (story components, story ideas and language, and episode structure), and plan score. The microstructural elements were the productivity measures, which included direct measures of the amount and diversity of vocabulary, and the amount and complexity of language used to tell the story. Specific measures analyzed were mean length of utterance (C-Units) in words (MLU-W), total number of different words (TNDW), and mean number of clauses per utterance (MNC-U). The MLU-W and MNC-U gave us an estimate of children's syntactic complexity and the amount of talk used to tell the story while the TNDW gave us an idea of the diversity of the child's lexicon.

Statistical models included mixed random and fixed effects. The assumptions of normality were met by analyzing skewness and kurtosis, inspection of data histograms, and visual inspection of the data for outliers. Bonferroni corrections were applied to follow-up univariate analyses pairwise comparisons by multiplying the p-value by the number of main comparisons made for each follow-up test, keeping the overall significance value at $p<.05$.

Values to consider significant group differences were set with p values equal or less than 0.05 . The effect size partial eta squared $\left(\eta_{\mathrm{p}}{ }^{2}\right)$ was calculated for each analyses. The partial eta squared value is the proportion of variance in a dependent variable that can be accounted for by the independent variable. There are currently no disciplinespecific interpretations of effect size in the field (Goldstein, 2005), thus guidelines following the interpretation of correlation analysis will be employed (Bedore, Peña, Garcia \& Cortez, 2005). Interpretations of partial eta squared will consider effect sizes between 0.8 and 1.0 very large, between 0.8 and 0.5 large, between 0.25 and 0.5 moderate, between 0.1 and 0.25 small, and less than 0.1 negligible. 


\section{Chapter 3: Results}

\section{STUdy ONE: PARALLEL STORIES ANALYSIS}

The goal of the first study was to determine whether the two books BR and TF yielded generally comparable stories in both English and Spanish across groups without the influence of mediation (i.e. at pretest). A previous study of CLD children (Peña, et al., 2006) demonstrated that the books were comparable in English for narrative and productive measures. The goal was to replicate these findings for English and expand the analysis to a comparison of the two books in Spanish. If the analysis yields comparable results for both stories within each language, this would justify collapsing pretest and posttest data for cohorts A and B (see Table 3) within the Control, LI, and TD groups.

\section{Method}

Pretest stories elicited from BR and TF were compared within Spanish and English. Of the 98 participants randomized to cohort A or B (including the children with and without language impairment), 46 children told BR in English, TF in Spanish, and 52 told TF in English and BR in Spanish at pretest (see Table 3 Research design). All 98 children told both stories, one in each language. For this analysis, TF and BR were compared in English and in Spanish using independent t-tests to compare the means for the total score of the narrative measures and several productive measures.

\section{Results}

Stories were compared using the following derived measures: total story scores (sum of story components, story ideas and language, and episode structure) and productivity measures (number of C-units, and MLU-words) using an independent samples t-test for equality of means. Consistent with Peña et al., (2006), there was no significant difference found between the BR and TF books respectively in English at pretest for total score $(M=22.83)$ and $(\mathrm{M}=23.02), t(96)=.114, p=.274$, for number of 
C-units, $(M=18.93)$ and $(M=19.75), t(96)=.524, p=0.675$, and for MLU-words $(M=$ 5.80) and ( $M=5.47), t(96)=1.018, p=0.332$. The analyses in Spanish also yielded comparable results between BR and TF respectively for total score $(M=24.87)$ and $(M=$ 25.11), $t(96)=.914, p=0.266$, for number of C-units $(M=20.52)$ and $(M=22.54), t(96)$ $=.156, p=.087$, and for MLU-words $(M=5.43)$ and $(\mathrm{M}=5.55), t(96)=.431, p=0.663$. Thus, because of the similarity in the stories within each language, data sets elicited using the TF and BR books were then collapsed within language for subsequent studies two and three.

Table 5

Parallel-forms reliability: Total scores and productivity measures of the two stories at pretest for Spanish and English.

\begin{tabular}{lllll}
\hline Language & Story & Total score (SD) & $\begin{array}{l}\text { No. C-Units } \\
(S D)\end{array}$ & MLU-W (SD) \\
\hline Spanish & Bird and His Ring & $24.87(6.62)$ & $20.52(8.23)$ & $5.43(1.17)$ \\
& Two Friends & $25.11(8.77)$ & $22.54(12.80)$ & $5.55(1.52)$ \\
English & Bird and His Ring & $22.83(9.05)$ & $18.93(7.02)$ & $5.80(1.85)$ \\
& Two Friends & $23.02(7.72)$ & $19.75(8.10)$ & $5.47(1.35)$ \\
\hline
\end{tabular}

\section{Discussion}

Study one focused on whether the two stories were parallel for within Spanish as well as within English. Results indicated no differences in narrative performance for the two wordless picture books Bird and His Ring and Two Friends within languages. These results are consistent with Peña et al. (2006) who found the same stories to be comparable for narrative and productivity measures in English across racial and ethnic groups and gender, providing evidence of parallel forms reliability. Thus, for subsequent studies two and three, data was collapsed across the stories within Spanish and within English.

\section{STUDY TWO: LANGUAGE EFFECTS AND TRANSFER}

This study had four goals. The analyses were designed to examine the effects of language (Spanish and English) on intervention and story production, and then to 
examine cross-language transfer of narrative skills, and language specific effects on both intervention and production.

First, the goal was to compare the language effects of Spanish or English story production on children's pretest and posttest stories. Bilinguals may produce stories that emphasize different elements with respect to the language of production (Fiestas \& Peña, 2004) or proficiency (Gutierrez-Clellen, 2002). In order to explore the possible patterns of differences due to the language of production, the narrative and productive measures were compared across Spanish and English.

The second goal was to compare the pretest to posttest changes in children's stories based on the language of intervention independent of language of story production. This analysis was concerned with whether children improved narrative and productive measures given intervention in Spanish or English. For this reason, conceptual scores (Bedore et al., 2005) of the narrative measures (best scores in Spanish or English) were used to look at overall change regardless of the language of production.

The third goal was to evaluate the cross-language transfer of skills learned during the Spanish or English interventions to stories produced in Spanish and English. Transfer was examined for children with and without LI. Findings that favor children's improvement in narratives at posttest when the language of intervention is not matched to the language of production would suggest the cross-language transfer of narratives skills. If, on the other hand, children's narratives improve only in the language that is matched to the language of intervention, this would indicate that narratives skills did not transfer across languages. For this analysis the gain score from pretest to posttest will be the measure of interest for story and productive measures.

The fourth goal concerned language-specific gains relative to the language of mediation. The gains scores will be compared from English and Spanish intervention to English and Spanish production. An interaction of language of intervention with language 
of production would suggest differences in children's productions in Spanish or English as a function of the language of intervention.

\section{Methods}

Participants. A total of 98 bilingual children participated in this study as described in the general methods. Children were divided into three groups consisting of 49 children with typical language development, 30 children with language-impairment and 19 typically developing who served as the no-treatment control group.

Procedures. As described above, children told two narratives, one in each language in counterbalanced manner. For the current study, analysis compared language of production effects in the control group of 19 children, and the two intervention groups of 30 bilingual children with language impairment and 49 bilingual children with typical language. To compare language of intervention effects, the two intervention groups were included and conceptual scores used, which includes the best score in either language. To compare language transfer and language specific gains analyses included the 30 children with language impairment and 49 children with typical language development.

The measures compared across these analyses were the total score, the three category scores that make up total score (story components, story ideas and language, and episode structure), plan score, and three measures of productivity (TNDW, MNC-U, and MLUW).

\section{Results}

\section{LANGUAGE OF PRODUCTION EFFECTS}

Narrative measures. To examine effects of the language of story production (Spanish or English) on measures of narrative skill for bilingual children with and without LI a three-way mixed model repeated-measures ANOVA was computed with the dependent measure of total score. The independent variables were the within-subjects factors time (pretest and posttest), and the language of story production (English and 
Spanish). The between-subjects factor was group (LI, TD, and Control). See Table 6 for an overview of scores in Spanish and English. The ANOVA yielded a main effect for language of production $F(1,95)=6.338, p=.013, \eta_{\mathrm{p}}{ }^{2}=.063$. The total scores in Spanish were significantly higher than English $(\mathrm{M}$ difference $=1.489)$. There was no interaction for group and language of production $F(2,95)=1.327, p<.270, \eta_{\mathrm{p}}^{2}=.027$ which indicates that scores were higher in Spanish regardless of group assignment (Control, TD or LI).

Next, the effect of the language of production was further explored by examining the category scores that make up total score and the plan score. A repeated-measures MANOVA was computed entering four dependent measures (story components, story ideas and language, episode structure, and plan score), and the independent variables were the within-subjects factors of time (pretest and posttest), and the language of story production (English and Spanish). The between-subjects factor was group (LI, TD, and Control). See Table 6 for an overview of the scores. The MANOVA yielded a main effect for the language of production $F(4,90)=3.576, p=.009, \eta_{\mathrm{p}}{ }^{2}=.137$. Univariate measures using pairwise comparisons (Bonferroni correction $=4$ ) revealed between language differences. As with the total score, Spanish, scores were significantly higher than English for story components ( $\mathrm{M}$ difference $=.786, p=.004$ ), and for plan score (M difference $=.297, p=.049$ ). Scores were comparable in Spanish and English for story ideas and language $(\mathrm{M}$ difference $=.287, p .=.399)$ and episode structure $(\mathrm{M}$ difference $=$ $.157, p .=.210)$. Consistent with total score, there was no interaction for group and language of production $\mathrm{F}(8,182)=.958, p=.470, \eta_{\mathrm{p}}^{2}=.041$. These results may indicate that language ability does not affect whether scores are better in Spanish or English.

Productivity measures. Finally, the effect of the language of story was explored on the productivity measures of total number of different words (TNDW), mean number of clauses per utterance (MNC-U), and mean length of utterance in words (MLU-W). These dependent measures were entered into three-way repeated-measures MANOVA. 
The independent variables were the within-subjects factors time (pretest and posttest), and the language of story production (English and Spanish). The between-subjects factor was group (LI, TD, Control). The productivity measures include direct measures of the amount and diversity of vocabulary, and the amount and complexity of sentence structure used to tell the story. Measures included mean length of utterance (C-Units) in words (MLU-W), total number of different words (TNDW), and mean number of clauses per utterance (MNC-U).

As with the narrative measures, the repeated measures MANOVA yielded a main effect for language of production $F(3,92)=12.051, p<0.001, \eta_{\mathrm{p}}{ }^{2}=.282$. Univariate analyses using pairwise comparisons (Bonferroni correction $=3$ ) revealed that the Spanish stories contained a significantly higher TNDW as compared to English ( $M$ difference $=4.44, p<.001)$. Thus, children used a higher productive lexicon in first language compared to second language. Stories were comparable in Spanish and English for measures of syntactic complexity, specifically MNC-U $(M$ difference $=.053, p .=$ .073 ) and MLU-W (M difference $=.217, p=.082$ ). See Table 6 for the productivity scores. As with the narrative measures, there was no interaction for group and language of production $\mathrm{F}(6,184)=1.189, p<.314,=.037$, indicating that performance in Spanish compared to English is not affected by language ability assignment. 
Table 6

Mean story and productive measures (SD) by Control, TD and LI groups for English and Spanish pretest and posttest

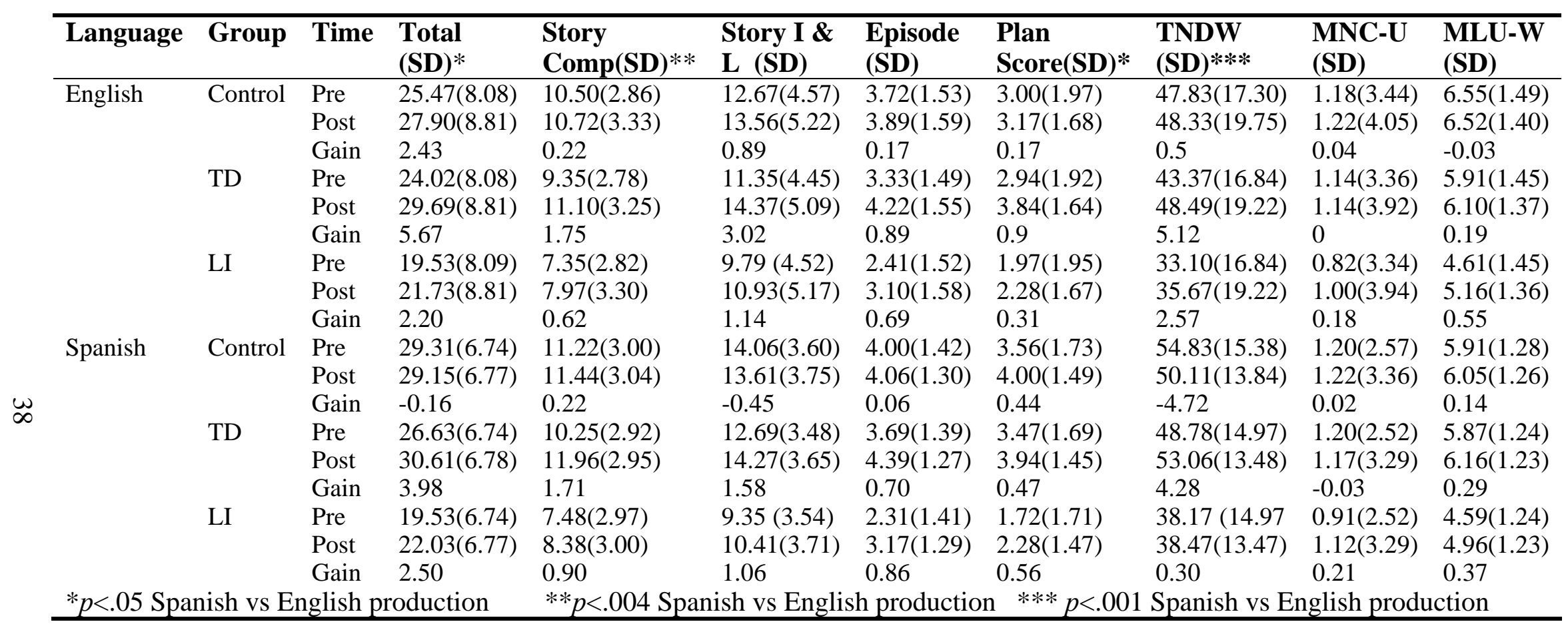




\section{LANGUAGE OF INTERVENTION EFFECTS}

Narrative measures. To explore the effect of the language of intervention independent of the language of story production, the conceptual scores were entered into the repeated measures ANOVA for total score as the dependent measure, and the independent variables were the within-subjects factors time (pretest and posttest) and language of intervention (Spanish and English). The between-subjects factor was language ability (LI and TD). The ANOVA demonstrated no main effect for the language of mediation $F(1,75)=.437, p=.511, \eta_{\mathrm{p}}^{2}=.006$. There was a main effect for time $F(1,75)=30.378=$ $p<.001, \eta_{\mathrm{p}}{ }^{2}=.288$, and language ability $F(1,75)=22.562, p<.001, \eta_{\mathrm{p}}{ }^{2}=.231$, (e.g. TD scores higher than LI scores) although the interaction of time and language ability was not significant $F(1,75)=2.233, p<.139, \eta_{\mathrm{p}}{ }^{2}=.029$. These results indicate that children scored higher at posttest, and TD children scored higher than LI children. See Table 7 for results.

For the narrative category scores there was no effect for the language of intervention $F(4,72)=.870, p=.486, \eta_{\mathrm{p}}{ }^{2}=.046$. Spanish or English had equal effects on children's inclusion of the elements that make up the category scores of story components, story ideas and language, episode structure, and the plan score. Consistent with total score, there was a main effect for time $F(4,72)=12.767, p<.001, \eta_{\mathrm{p}}{ }^{2}=.415$ and for language ability $F(4,72)=8.501, p<.001, \eta_{\mathrm{p}}{ }^{2}=.321$. The interaction of time and language ability was not significant $F(4,72)=1.530, p<.203, \eta_{\mathrm{p}}{ }^{2}=.078$. Thus, children scored higher at posttest, and TD children scored higher than LI children. See Table 7 for results. 


\section{Table 7}

Mean conceptual scores (SD) for story measures by Control, TD and LI groups for English and Spanish intervention

\begin{tabular}{llllllll}
\hline LOI & Group & Time & $\begin{array}{l}\text { Total } \\
\text { (SD) }\end{array}$ & $\begin{array}{l}\text { Story } \\
\text { Comp(SD) }\end{array}$ & $\begin{array}{l}\text { Story I \& } \\
\text { L (SD) }\end{array}$ & $\begin{array}{l}\text { Episode } \\
\text { (SD) }\end{array}$ & $\begin{array}{l}\text { Plan } \\
\text { Score(SD) }\end{array}$ \\
& TD & Pre & $29.32(7.41)$ & $11.4(2.96)$ & $13.96(4.02)$ & $3.96(1.44)$ & $3.96(1.76)$ \\
& & Post & $35.20(7.40)$ & $13.28(3.31)$ & $17.08(3.93)$ & $4.84(1.12)$ & $4.68(1.28)$ \\
& & Gain & 5.88 & 1.88 & 3.12 & 0.88 & 0.72 \\
& LI & Pre & $24.38(7.56)$ & $8.94(3.02)$ & $12.75(4.1)$ & $2.69(1.47)$ & $2.69(1.80)$ \\
& & Post & $28.38(7.55)$ & $10.31(3.38)$ & $13.94(4.02)$ & $4.13(1.15)$ & $3.13(1.31)$ \\
& & Gain & 4.00 & 1.37 & 1.19 & 1.44 & 0.44 \\
Spanish & TD & Pre & $30.42(7.72)$ & $11.67(3.09)$ & $14.54(4.19)$ & $4.21(1.50)$ & $4.17(1.84)$ \\
& & Post & $35.25(7.71)$ & $13.71(3.45)$ & $16.54(4.10)$ & $5.00(1.17)$ & $4.54(1.34)$ \\
& & Gain & 4.83 & 2.04 & 2.00 & 0.79 & 0.37 \\
& LI & Pre & $22.64(9.21)$ & $9.21(3.03)$ & $10.71(4.10)$ & $2.71(1.47)$ & $2.29(1.80)$ \\
& & Post & $24.79(7.55)$ & $9.43(3.38)$ & $11.86(4.02)$ & $3.5(1.15)$ & $2.71(1.31)$ \\
& & Gain & 2.15 & 0.22 & 1.15 & 0.79 & 0.42 \\
\hline
\end{tabular}

TRANSFER EFFECTS: THE LANGUAGE OF MEDIATION AND PRODUCTION

Narrative measures. To evaluate the cross-language transfer of skills learned during the Spanish or English interventions, 2 three-way ANOVAs, one for the LI and one for the TD group were computed. The dependent variable was the gain score from pretest to posttest for total score. The independent variables were language of intervention (Spanish and English) and matching (matched and unmatched) referring to whether the language targeted in intervention was matched or unmatched to the language of production. The ANOVA demonstrated no main effect on total score for matching (e.g. whether the language of intervention was matched or unmatched to the language of production) for children with LI $F(1,30)=.028, p=.868, \eta_{\mathrm{p}}{ }^{2}=.001$ or for children who are TD $F(1,45)=1.387, p=.245, \eta_{\mathrm{p}}{ }^{2}=.030$. Children with LI and TD were as likely to improve on the total score whether the language of intervention was matched or 
unmatched to the language of story production. This result indicates that there was transfer from the language used in intervention to the unmatched language used to tell the story (e.g. Spanish intervention to English production or English intervention to Spanish production).

For language-specific gains as a function of the language of intervention, there was a not a significant interaction between the language of intervention and the language of production (matched and unmatched) for the LI $F(1,30)=.002, p=.967, \eta_{\mathrm{p}}{ }^{2}=.000$, and TD groups $F(1,45)=1.234, p=.272, \eta_{\mathrm{p}}{ }^{2}=.027$. Results indicate that there was comparable change in the stories produced in Spanish or English regardless of the language of instruction. Thus, there was no need to proceed with the further examination of individual scores making up the total score. See Table 8 for results.

Productivity measures. Three 3-way ANOVAS were computed for the productivity measures for the TD and LI groups to observe effects on measures of productivity. The dependent measures were the gain scores from pretest to posttest for TNDW, MNC-U and MLU-W. The independent variables were language of intervention (Spanish and English) and matching (matched and unmatched) referring to whether the language targeted in intervention was matched or unmatched to the language of production. The ANOVAs yielded a main effect for the stories produced in the language that matched the language of intervention compared to those that were in the unmatched language on MNC-U for LI children $F(1,28)=7.885, p<.009, \eta_{\mathrm{p}}{ }^{2}=.220$. Children with LI demonstrated a greater pretest to posttest change in clauses per utterance in the language that was unmatched to in the language of intervention ( $M$ difference $=.349$ ) as compared to the language that was matched to the language of intervention ( $M$ difference $=.109)$. This difference was not observed in children who were $\operatorname{TD} F(1,47)=.607, p=$ $.440, \eta_{\mathrm{p}}{ }^{2}=.013$. There were no other effects for matched vs. unmatched language of production on the productivity measures for LI and TD children for TNDW or MLU-W ( $F$ values $<1.197, p<.281, \eta_{\mathrm{p}}^{2}<.039$ for all measures). 
Concerning the question of language-specific gains as a function of the language of intervention, there was a non-significant interaction between the language of intervention and the language of production (matched or unmatched to the language of intervention). The results demonstrate comparable change in stories produced in either Spanish or English regardless of the language of intervention. Thus, there were no language specific benefits from mediation in one language over another for this group of fairly balanced bilingual children when they told stories in either Spanish or English ( $F$ values $<0.447, p<.509, \eta_{\mathrm{p}}{ }^{2}<.012$ for all measures). See Table 8 for results. 
Table 8

Gain scores (SD) for story and productive measures for stories in Spanish and English matched and unmatched to the language of intervention by TD and LI groups.

\begin{tabular}{|c|c|c|c|c|c|c|c|c|c|}
\hline Group & $\begin{array}{l}\text { LOI } \\
\text { matched } \\
\text { to } \\
\text { production }\end{array}$ & $\begin{array}{l}\text { Language } \\
\text { of story } \\
\text { production }\end{array}$ & $\operatorname{Total}(S D)$ & $\begin{array}{l}\text { Story } \\
\text { Comp }(S D)\end{array}$ & $\begin{array}{l}\text { StoryI\&L } \\
(S D)\end{array}$ & $\begin{array}{l}\text { Episode } \\
(S D)\end{array}$ & $\begin{array}{l}T N D W \\
(S D)\end{array}$ & $\begin{array}{l}M N C-U \\
(S D)\end{array}$ & $\begin{array}{l}M L U-W \\
(S D)\end{array}$ \\
\hline \multirow[t]{4}{*}{ LI } & yes & English & $3.38(7.27)$ & $0.50(2.66)$ & $1.75(4.91)$ & $1.13(1.54)$ & $2.88(13.02)$ & $-0.07(.54)$ & $0.48(1.63)$ \\
\hline & yes & Spanish & $1.63(6.74)$ & $0.06(2.69)$ & $0.94(3.51)$ & $0.63(1.36)$ & $.643(13.92)$ & $0.17(.58)$ & $0.07(1.74)$ \\
\hline & no & English & 3.19(6.67) & $1.13(3.16)$ & $1.06(3.23)$ & $1.00(1.51)$ & $0.00(18.00)$ & $0.24(.60)$ & $0.63(1.18)$ \\
\hline & no & Spanish & $1.31(6.55)$ & $0.00(2.92)$ & $0.88(3.48)$ & $0.44(1.46)$ & $2.21(19.24)$ & $0.46(.64)$ & $0.62(1.26)$ \\
\hline \multirow[t]{4}{*}{ TD } & yes & English & $6.68(6.74)$ & $2.24(2.68)$ & $3.32(4.23)$ & $1.12(1.67)$ & $5.84(12.75)$ & $0.00(.39)$ & $0.42(1.38)$ \\
\hline & yes & Spanish & $4.73(5.66)$ & $2.27(3.01)$ & $1.59(3.05)$ & $0.86(1.61)$ & $6.13(12.20)$ & $0.01(.38)$ & $0.17(1.32)$ \\
\hline & no & English & $3.56(6.93)$ & $1.28(2.89)$ & $1.72(4.49)$ & $0.56(1.56)$ & $2.52(14.76)$ & $-0.60(.33)$ & $0.40(1.40)$ \\
\hline & no & Spanish & $4.63(9.37)$ & $1.36(4.53)$ & $2.68(5.29)$ & $0.59(1.40)$ & $4.38(14.13)$ & $-0.01(.31)$ & $-.06(1.34)$ \\
\hline
\end{tabular}




\section{Discussion}

Questions of Study two were concerned with the language of intervention, production, language specific effects of intervention on production, and cross-language transfer of narrative skills. The language of intervention does not appear to affect bilingual children's performance. The conceptual scores indicate that children learn the concepts in one or both of their languages and demonstrate equal gains given intervention in Spanish or English. However, examination of the language of story production reveals that the use of Spanish or English to tell the story affects children's use of macro and microstructural elements. Generally stories in Spanish were rated higher than the English stories. The similarities between the gains in children's stories whether they were matched or unmatched to the language of intervention provided an indication that there was cross-language transfer. Examination of cross-language transfer indicated that the macrostructural aspects of narration transferred equally to the language of production that was matched and non-matched to the language of intervention. Microstructural elements did not transfer equally for the matched and non-matched language of production. These findings might be related to typological differences in the grammatical structures that are specific to each language and to language ability. There were no specific differences related to the language of intervention on the language of production. Children's narratives improved equally in Spanish and English regardless of the language of intervention. It may be that there was not sufficient power reveal any differences.

\section{STUDY 3: LANGUAGE ABILITY DIFFERENCES}

The two analyses in this study were concerned with examining differences in performance over time for children with and without language impairment. Results from the previous study indicate no differences in performance due to the language of intervention, thus for this study scores across language of intervention were collapsed within the TD and LI groups with respect to the language of intervention, and 
comparisons were made to a non-intervention control group. For children receiving intervention, clinician ratings of modifiability were compared for children with and without language impairment and also were compared for intervention in Spanish and English.

\section{Method}

To examine patterns of change relating to language ability and comparison to a Control, narrative and productive measures were examined for the LI, TD and the Control group. The LI group consisted of 30 children who were language impaired, the Control group consisted of 19 children with typical language development who did not receive mediation, and the TD group consisted of 49 children with typical language development who did receive mediation. The LI and TD groups received intervention. See Table 1 for group descriptions. The dependent measures compared across this analyses were the total score, the three category scores that make up the total score (story components, story ideas and language, and episode structure), plan score (See Table 4 for an overview), and three measures of productivity (TNDW, MNC-U, and MLU-W). To compare differences in the modifiability of the children based on language status (LI or TD), and to determine whether the language of intervention had an effect on children's modifiability, the dependent measure modifiability scores were compared between the 30 children with LI and the 49 children with TD language. The modifiability scores of children with and without LI were compared across groups and across the language of intervention.

\section{Results}

\section{LANGUAGE ABILITY EFFECTS}

Narrative measures. To examine the effects of language ability (LI and TD) on task performance over time, and compare the effects of intervention with a control group, 
a three-way mixed model repeated-measures ANOVA was computed with the dependent measure total score, and the independent variables were the within-subjects factors of time (pretest and posttest), and the language of story production (English and Spanish). The between-subjects factor was group (LI, TD, Control). The ANOVA revealed main effects for time $F(1,95)=23.951, p<.001, \eta_{\mathrm{p}}{ }^{2}=.201$, group $F(2,95)=13.350, p<.001$, $\eta_{\mathrm{p}}{ }^{2}=.219$, and a time by group interaction $F(2,95)=4.251, p=.017, \eta_{\mathrm{p}}{ }^{2}=.082$. Because the main effects are subsumed in the interaction these are further explored using pairwise comparisons (Bonferroni correction factor $=3$ ). The pairwise comparisons revealed significant increases from pretest to posttest for the LI $(M$ difference $=2.350, p .=.045)$, and TD groups $(M$ difference $=4.827, p<0.001)$, but not for the Control group ( $M$ difference $=1.132, p=.346$ ). Thus, the LI and TD groups appeared to benefit from the intervention whereas the Control group showed no improvement.

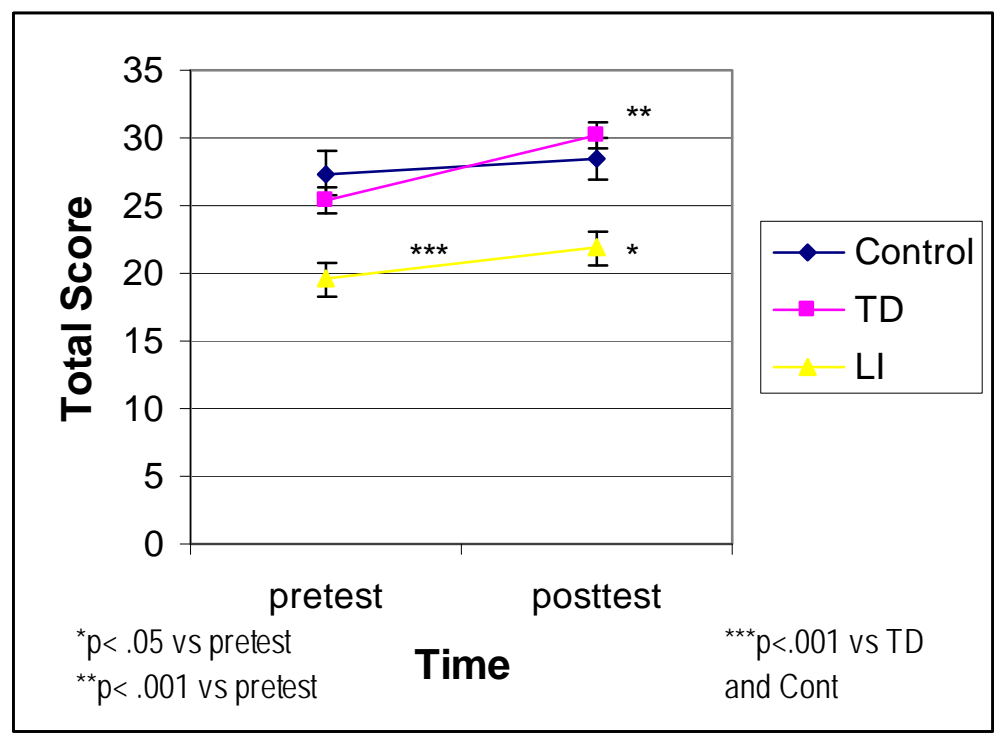

Figure 1. Comparison of pretest and posttest total scores $(+S E)$ for Control, TD and LI groups.

A repeated-measures MANOVA was computed entering four dependent measures (story components, story ideas and language, episode structure, and plan score). The 
independent variables were within subjects factors of time (pretest and posttest), and the language of story production (English and Spanish). The between-subjects factor was group (LI, TD, Control). The MANOVA yielded a similar pattern for the category and plan scores as was observed on total score. There were main effects for time $F(4,90)=$ 7.831, $p<.001, \eta_{\mathrm{p}}{ }^{2}=.258$, group $F(8,182)=4.775, p<.001, \eta_{\mathrm{p}}{ }^{2}=.175$, and a time by group interaction $F(8,180)=2.223, p=.028, \eta_{\mathrm{p}}{ }^{2}=.090$. Because the main effects are subsumed in the interaction, these are further explored using pairwise comparisons (Bonferroni correction $=6$ ). Pairwise comparisons revealed that the TD group improved significantly from pretest to posttest for all of the category scores, specifically story components, $(M$ difference $=1.735, p .<0.001)$, story ideas and language $(M$ difference $=$ 2.296, $p<.001)$, episode structure ( $M$ difference $=.796, p<.001)$, and plan score $(M$ difference $=.684, p<.001$ ). The LI group significantly improved only for episode structure $(M$ difference $=.776, p .<.00) 1$ but not for story components $(M$ difference $=$ $.276, p=.538)$, story ideas and language $(M$ difference $=1.103, p=.396)$, nor plan score ( $M$ difference $=.431, p=.444)$. The Control group did not improve for any measure. Specifically, for the control group no significant improvement was documented for story components $(M$ difference $=.222, p=.696)$, story ideas and language $(M$ difference $=$ $.222, p=.732)$, episode structure ( $M$ difference $=.111, p=.648)$, or plan score $(M$ difference $=.306, p=.241)$. 


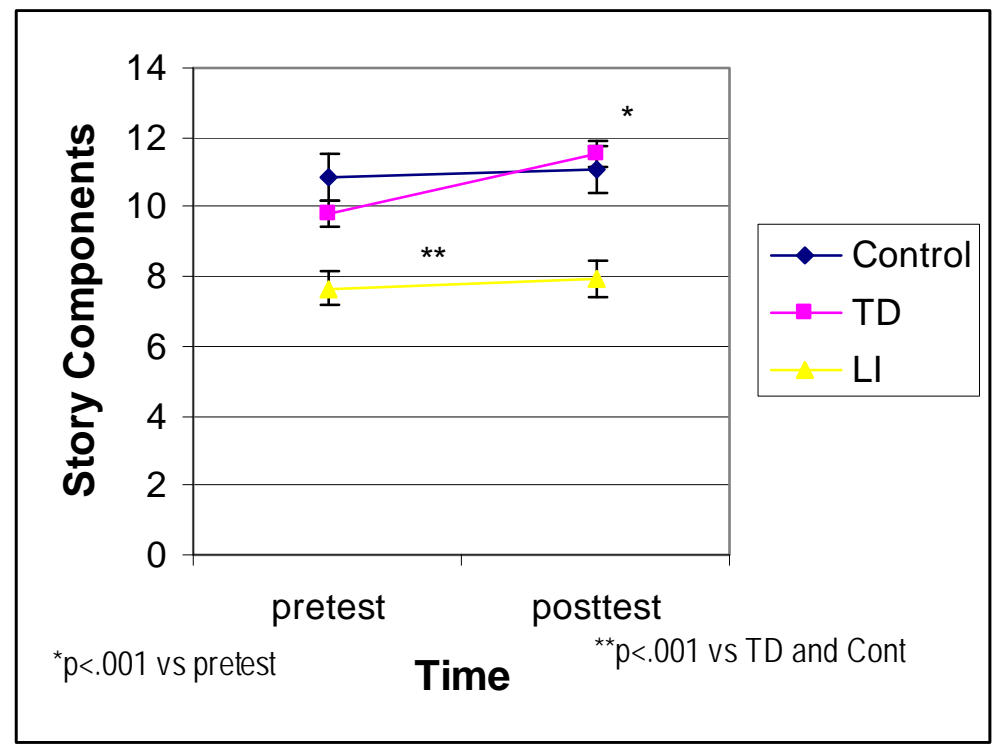

Figure 2. Comparison of pretest and posttest story components scores $(+S E)$ for Control, TD and LI groups.

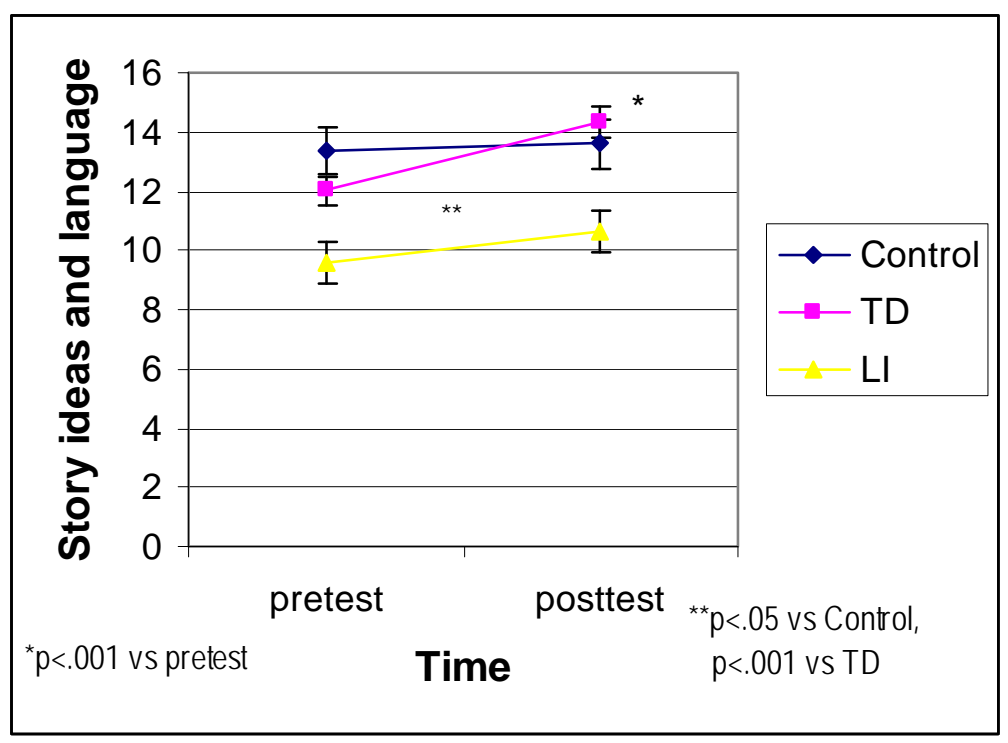

Figure 3. Comparison of pretest and posttest story ideas and language scores $(+S E)$ for Control, TD and LI groups. 


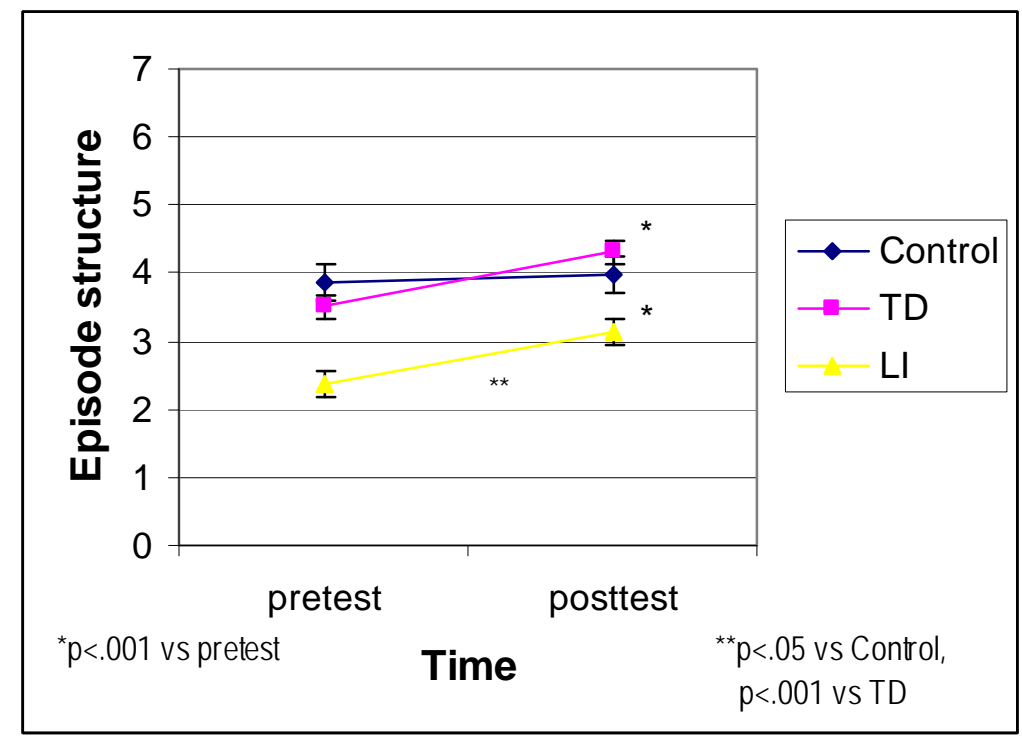

Figure 4. Comparison of pretest and posttest episode structure scores $(+S E)$ for Control, TD and LI groups.

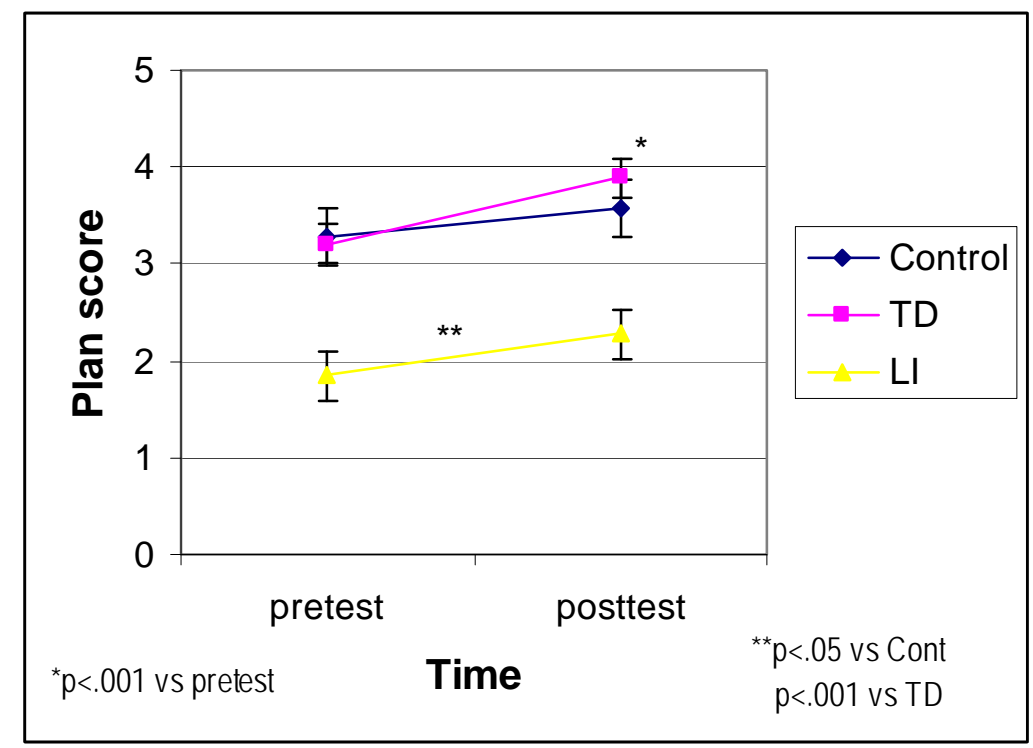

Figure 5. Comparison of pretest and posttest plan scores $(+S E)$ for Control, TD and LI groups.

Productivity measures. A repeated-measures MANOVA was computed entering the dependent measures (TNDW, MNC-U and MLU-W), time (pretest and posttest), and the independent variables were the within-subjects factor the language of story 
production (English and Spanish). The between-subjects factor was group (LI, TD, Control). The MANOVA yielded main effects for group $F(6,184)=5.750, p<.001, \eta_{\mathrm{p}}{ }^{2}=$ .158 , a trend for the interaction of time by group $F(6,184)=1.909, p=.081, \eta_{\mathrm{p}}{ }^{2}=.059$, but a non-significant main effect for time $F(3,92)=1.880, p=.138, \eta_{\mathrm{p}}{ }^{2}=.058$.

Univariate analyses of the group effects as observed in pairwise comparisons (Bonferroni correction $=9)$ demonstrated that all productivity measures for the LI were significantly lower than the TD and Control groups. Specifically, the LI group used fewer TNDW than TD $p<.001$ and Control $p=0.009$, fewer clauses per utterance (MNC-U) than TD $p<.001$ and Control $p<.001$, and fewer words per utterance (MLUW) than TD $p .<.001$ and Control $p .<.001$. There were no differences between the TD and Control groups for any of the productivity measures $(p<.620)$.

Univariate analyses were used to explore the marginal interaction (Bonferroni correction $=9$ ). Pairwise comparisons demonstrated a significant increase from pretest to posttest for the TD group for TNDW only $(M$ difference $=4.704) p .=0.045$, but not for MNC-U $(M$ difference $=-.014) p=.784$ nor MLU-W $(M$ difference $=.237) p=.107$. For the LI group, there was a significant increase in MNC-U only $(M$ difference $=.193) p=$ .036 , but not for TNDW (difference $=1.433) p=.495$ nor MLU-W $(M$ difference $=.457)$ $p=.144$. There were no significant increases in productivity measures from pretest to posttest for the Control group, specifically none for TNDW $(M$ difference $=-2.111) p=$ .437 , MNC-U $(M$ difference $=.031) p=.713$, nor MLU-W $(M$ difference $=.059) p=$ .805. Overall, while the TD children improved in the number of different words that they used there was no pretest to posttest change in the Control group not receiving intervention. LI children used more complex sentences than at pretest. 


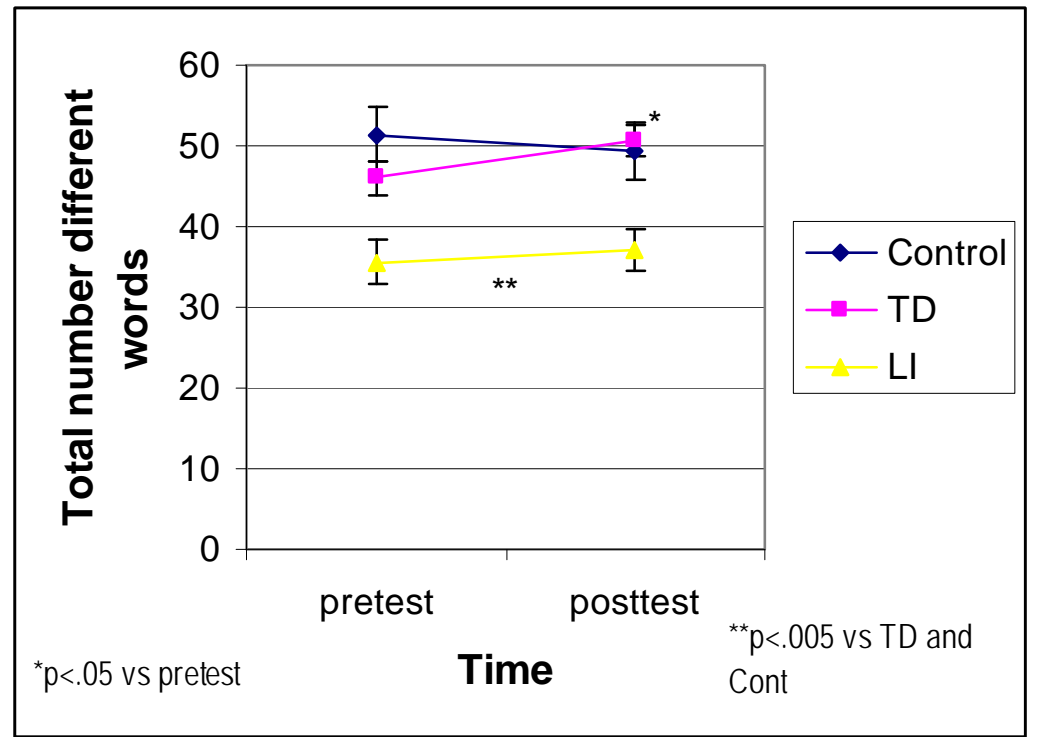

Figure 6. Comparison of pretest and posttest total number of different words $(+S E)$ for Control, TD and LI groups.

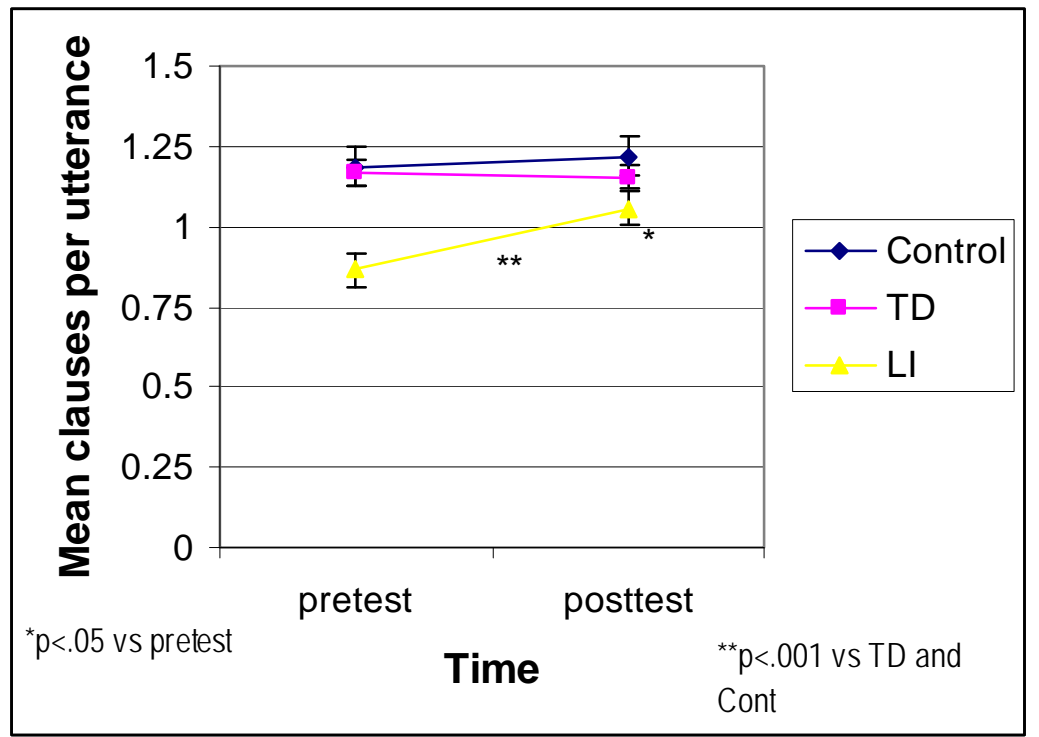

Figure 7. Comparison of pretest and posttest mean clauses per utterance $(+S E)$ for Control, TD and LI groups. 


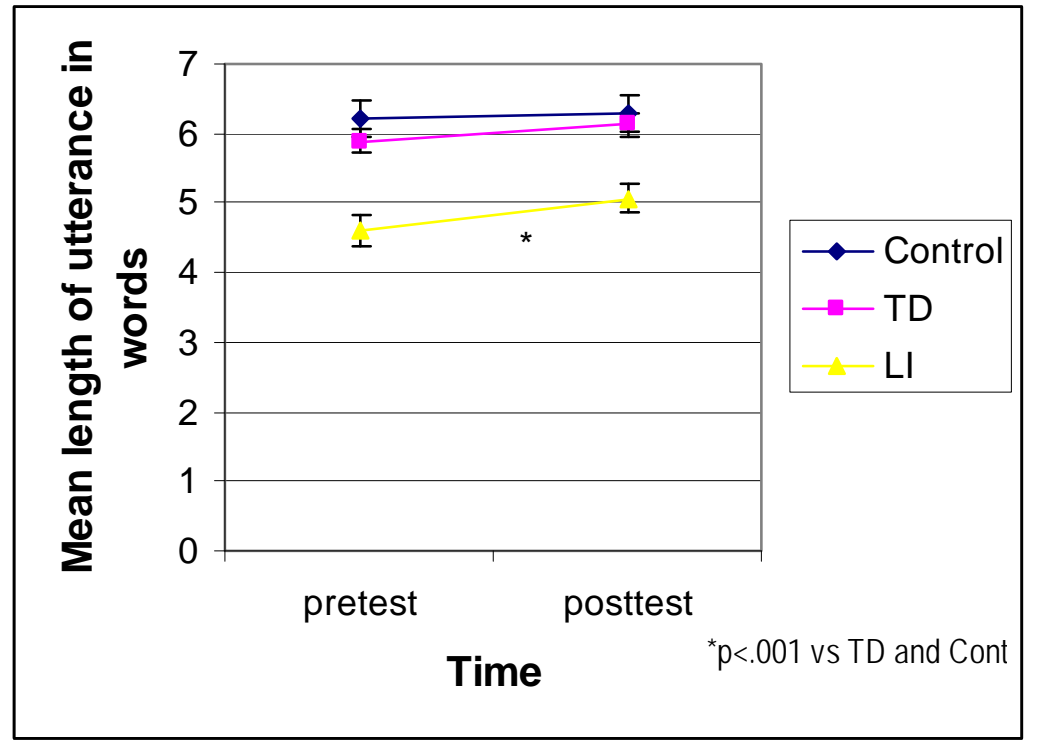

Figure 8. Comparison of Control, TD and LI group pretest and posttest mean length of utterance in words $(+S E)$.

\section{MODIFIABILITY}

To examine differences in modifiability based on language ability and to compare modifiability given intervention in Spanish and English, a two-way ANOVA was run with the dependent measure modifiability score. The independent variables were the between-subjects factors of language status (LI or TD) and language of mediation (Spanish or English). The dependent variable was modifiability score. There was a main

effect for language ability $F(1,71)=33.721, p<0.001, \eta_{\mathrm{p}}{ }^{2}=.322$. Children who were typically developing had significantly lower modifiability scores, indicating that they were more modifiable than children with LI. The effect of language of mediation demonstrated a trend, although not significant $F(1,71)=3.643, p=.060, \eta_{\mathrm{p}}{ }^{2}=.049$, appearing that children who received intervention in English needed slightly more support. 


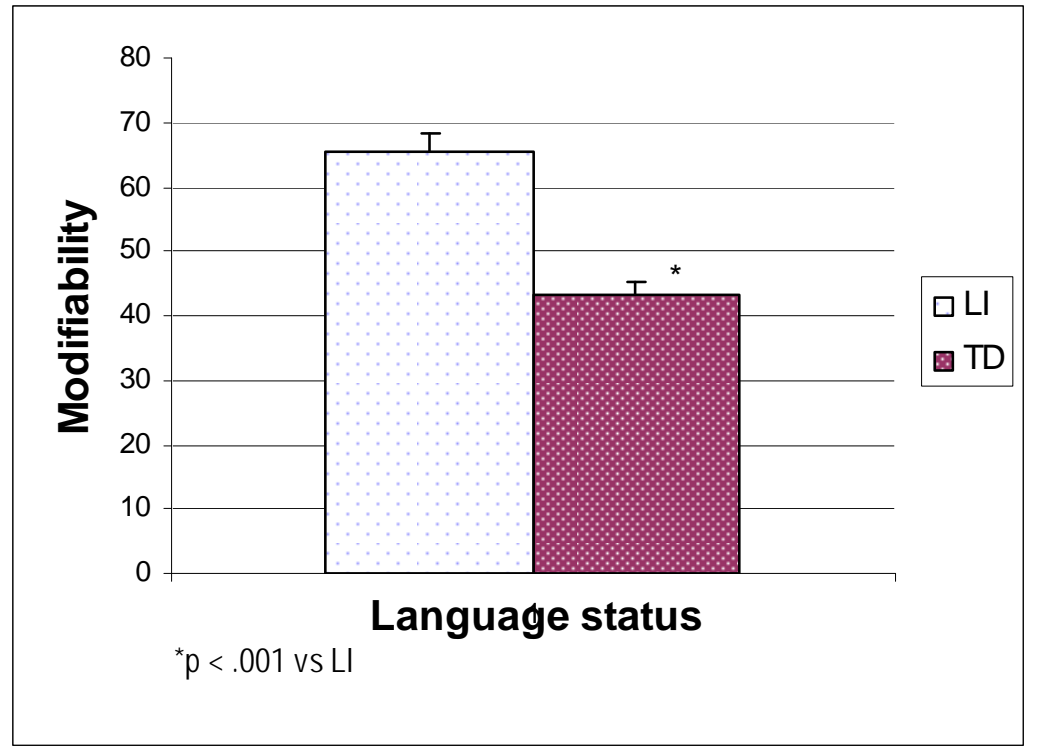

Figure 9. Comparison of Modifiability scores $(+S E)$ for TD and LI groups.

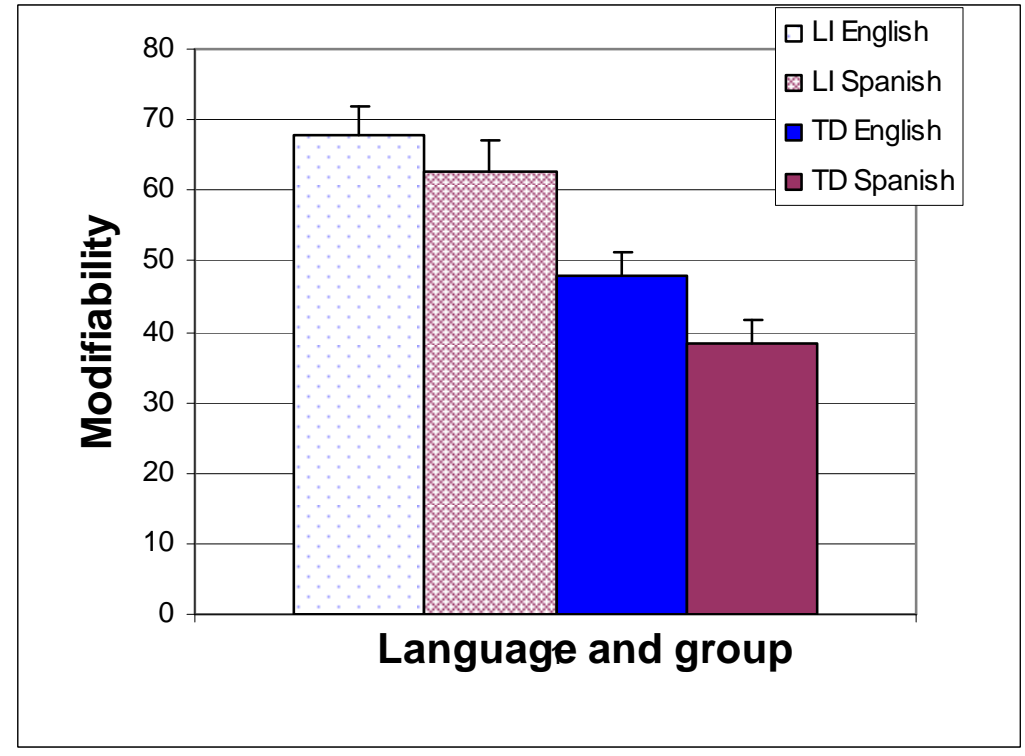

Figure 10. Comparison of modifiability scores $(+S E)$ for groups by language of intervention. 


\section{Discussion}

The results of Study 3 indicate that there are differences in children's pretest to posttest changes in narrative skills due to language ability (TD and LI). Children who are typically developing show greater improvement in their stories from pretest to posttest. Children with language impairment start out lower, and they do not demonstrate the same improvement seen in the narratives of the TD children. Children who did not receive the intervention did not improve their stories, indicating that the improvement demonstrated by the TD and LI groups was not a practice effect. Additionally, modifiability scores were also different for the LI and TD groups. Clinicians who were blind to the children's language ability rated the TD children as more modifiable than the LI children. Intervention in English for these children learning English as a second language may impact modifiability scores slightly, although the effect was not significant. Thus, modifiability scores may need to be interpreted with more caution for bilingual children with respect to the language of intervention. 


\section{Chapter 4: DISCUSSION}

The goal of this study was to examine the response to intervention of bilingual children with and without typically developing language on narrative performance, a skill that is highly correlated with academic performance. Of practical and theoretical interest was the comparison of narrative performance by language and ability.

\section{LANGUAGE OF PRODUCTION, INTERVENTION, AND TRANSFER}

The results of the current research indicate that children's performance changed equally given intervention in English or Spanish, and that children's performance in Spanish was stronger overall (total score, story components, plan score, and TNDW) for these bilingual first and second grade children with and without language impairment. Differential production in Spanish and English is consistent with the notion that a bilingual may demonstrate unique performance in each language (Grosjean, 1989). Additionally, children appeared to transfer elements of narrative macrostructure equally across languages.

From an input perspective, these children were still using and practicing Spanish more than English (See Table 1). Using the unified model to predict performance, we would expect that more cultural and linguistic input and practice in Spanish as compared to English would predict stronger performance in Spanish, yet cognitive skills such as those acquired as a result of participating in the MLE sessions would be directly tied to underlying cognition, and thus predicted to transfer across languages. The unified model explains the findings that intervention in Spanish or English equally affected performance as demonstrated by the examination of conceptual scores, which takes children's best score in either Spanish or English for each item at pretest and posttest without the confounding factors of the language of production. A bilingual uses a single cognitive system, but input, use, experience, and proficiency may effect how a bilingual performs 
in each language. Cognitive skills leading to improved story-telling transferred across languages equally, despite the language of intervention. The explanation for this finding may lie within the nature of the MLE sessions. The sessions, although standardized for content, were customized the children's individual abilities. It was the responsibility of the clinician to provide individualized feedback, examples, and to help the child to increase their current level of functioning throughout the session. The importance of mediated learning is that it is a cognitive intervention, which teaches children cognitive strategies leading to independence. Thus, as long as the clinician provided comprehensible input (Krashen, 1985) during the session, children were likely to exhibit change. These results speak to the power of mediated learning causing a cognitive change regardless of whether it occurred in what was likely to be the child's stronger language.

Stronger performance in Spanish for sequential bilinguals in the early elementary years is consistent with previous research on bilingual narrative skills where children used more TNDW (Fiestas, et al., 2003; Miller et al., 2006), and scored higher on plan score (Fiestas, et al., 2003) in Spanish than English. The findings of more TNDW in Spanish for this age group is also consistent with the work of Kohnert, Bates \& Hernandez (1999) and Kohnert and Bates, (2002) whose work suggests an age-related shift in speed and accuracy of vocabulary comprehension and production from the first language to second language (between 8 to 13 years for production) likely from increased academic exposure to English. These measures, along with story components, could be strongly tied to language proficiency. Some of the subcomponents in story components are organizational and cohesive measures such as causal relationships and temporal order of events. With respect to cultural influences, another subcomponent of story components is character information. Previous research (McCabe \& Bliss, 2003; Silva \& McCabe, 1996) has described the narratives of Latino children as being descriptive of family and friends. Children might be demonstrating a cultural difference highlighting 
different information dependent on the language of story (e.g. Fiestas \& Peña, 2004; Silliman et al., 2002; Soter, 1988; Stavans, 2003).

Comparable across languages were the story ideas and language, episode structure, and measures of syntactic complexity. Several subcomponents of the category score of story ideas and language may be measurements that are more idiosyncratic such as the use of dialogue in a story, complexity of ideas and creativity. These measures may be more independent of language, and more dependent on personality, exposure to different story types, and pragmatics. Additionally, episode structure was comparable across languages. Previous work (Fiestas et al., 2003) shows that bilingual children will include equal numbers of internal responses across languages and demonstrate stories that are equally complex, but may use different episode elements to get there (Fiestas \& Peña, 2004). At this age, children may be practicing inclusion of episode elements when they retell stories on academic measures of story comprehension in the first and second grade. Children are often taught to include who, what, where, why, and when information when retelling a story, which provides children with an organizational structure akin to story grammar, so this may be a skill that they have acquired in both languages.

While children improved in both languages regardless of the language of intervention, children made improvements in slightly different ways with respect to language typology and the rhetorical options available in English and Spanish. For instance, in Spanish children may have differentiated characters of different sizes by using the diminutive forms "ita" and "ito" on the end of the animal names, ("pajarito" instead of "pájaro") while in English children referred to the "little bird".

One reason for syntactic complexity (MNC-U and MLU-W) looking similar in Spanish and English is that our method of dividing C-Units in Spanish is slightly different than English due to the pro-drop nature of Spanish (see transcription protocol in the methods section). This method may penalize Spanish speaker’s (Miller, et al., 2006) 
mean utterance length. Recall that a difference was expected when comparing Spanish to English for MNC-U and MLU-W due to the higher subordination in Spanish as compared to English (Berman and Slobin, 1994).

\section{LANGUAGE ABILITY DIFFERENCES}

Results of the current study are consistent with previous work in English demonstrating differential pretest to posttest change for children with and without language impairment following MLE (Peña, et al., 2006; Peña, Iglesias \& Lidz, 2001; Peña, Quinn, \& Iglesias, 1992), and previous work documenting poor narrative performance for children with LI, specifically in the micro and macrostructural aspects of storytelling (Gillam \& Carlile, 1997; Hayward, Gillam, \& Lien, 2007; Liles, 1985a, Liles, 1985b, Liles, 1987, Merrit \& Liles, 1987). The current study indicates that bilingual children with LI demonstrate poorer performance in both languages as compared to bilingual children with typical language development, and little overall change from pretest to posttest in either language.

For bilingual children, there are differential patterns of pretest to posttest differences between children with and without language impairment as compared to a control group that did not receive intervention. Recall that the control group made no significant improvement, whereas the LI group scored lower overall for measures of micro and macrostructure than the TD and Control groups. Further, for the LI group pretest to posttest improvement was only evident for episode structure and MNC-U whereas the TD group made significant pretest to posttest improvement for all of the narrative category measures and TNDW. The improvements seen in the TD group for TNDW is consistent with Peña et al. (2006) who found that TNDW was the productivity measure with the highest classification accuracy to distinguish between LI and TD children. Gains for the TD group were greater in magnitude than gains made by the LI group. See Table 4 for pretest to posttest difference for the groups. These results are consistent with Peña et al, (2006) who documented significant differences between the 
TD and LI groups, and no significant gains made by the Control group. The patterns of pretest to posttest differences between the TD and LI groups indicate promising results for the potential application of DA to differentiate LI and TD children who are bilingual.

There were qualitative differences in children's stories from pretest to posttest. The kinds of changes that children made mirrored the targets taught during the MLE sessions. For instance, children learned to elaborate more on character and setting information. At pretest, children frequently did not talk about the characters more than naming the type of animal, and no setting information was included. At posttest, children named the characters, or talked about physical characteristics and emotions. Setting information was included by looking at picture cues such as statements that it was day or night when there was a sun or stars in the picture, and more specific setting information such as in the forest, the desert, or the mountains. Additionally, children elaborated more on the problem and what caused it, the attempts to solve it and the conclusion which increased the episode structure score and children wrapped up their story with a ending statement such as "and then they were friends again" whereas at pretest stories ended abruptly with the end of the action. Because children elaborated more and told stories that were more organized in terms of structure, it is not surprising that the amount of different vocabulary words, and length and complexity of their sentences increased at posttest. The children that improved in these aspects were the children that benefited from the specific aspects of narration targeted in the MLE sessions.

Children's modifiability scores yield significant differences between the LI and TD groups, with LI children demonstrating less modifiability, which is consistent with Peña et al. (2006) who found that modifiability was the most accurate measure in classifying LI and TD children. The current study contributes to these findings with evidence that children with and without language impairment present different modifiability profiles regardless of the language of intervention. But note that as a function of the language of intervention, modifiability scores were marginally higher for 
children who received intervention in English. Recall that although these children were bilingual, their stories were stronger in Spanish, (first language) than English (second language), indicating stronger proficiency in the first language than the second language. Clinicians had to ensure that they were providing comprehensible input. Thus, clinician's impressions of children receiving intervention in English was that they required more support (e.g. providing more examples, simplifying language, or modifying for language proficiency) in the second language during the MLE.

From a cognitive perspective, the typically developing children participating in the MLE sessions learned to use particular cognitive tools, which allowed them to independently tell better stories. Children without strong language-learning abilities, as is the case with language impairment, did not learn to efficiently use the tools and strategies taught in the context of story instruction. As examined by Peña, et al. (2007), clinician evaluations of children's modifiability, specifically error awareness and ability to change strategies in the context of narrative instruction led to accurate decisions about which children were language impaired. Modifiability evaluations were also predictive of which children would improve their stories at posttest. To improve stories, some examples of cognitive tools used and taught during MLE were applying, attending, and organizing new information, choosing and remembering when to use particular strategies, making inferences, discriminating between relevant and irrelevant information, selfmonitoring for errors, and generalizing these skills to new types of stories. These cognitive tools and strategies are tied to cognition, and children who learned to use these tools were able to transfer their use across languages.

\section{IMPLICATIONS FOR TESTING, LIMITATIONS, AND FUTURE DIRECTIONS}

The findings from this study have implications for assessment practices. The differential performance across languages highlights the need to assess bilingual children's performance in both languages for a better picture of language skills. Although in general, children performed better in English, children at this age are starting to 
practice and use academic skills in the second language, thus testing in both languages will prevent underestimation of children's skills. Results also demonstrate the importance of understanding children's home and academic exposure to language use to consider performance and the language of mediation to be used. For children less proficient in the second language, more skill and support could be necessary during mediation. In scoring modifiability, cautious interpretations of support should be used because of more support may be required for children with low language proficiency and should not be confused with the amount of support needed because of low language ability. Thus, high quality mediated learning procedures need to be employed and individualized to children's specific needs and abilities.

Limitations of the present study are a possible lack of power to observe differences due to the language of intervention on the respective languages used to produce the story. Recall that half of the children in each group received intervention in Spanish and the other half in English. It may be that we were unable to detect perhaps subtle changes in story production given intervention in one language or another.

Further studies of the dynamic assessment of narratives for bilingual children would be designed for discrimination and classification of the items which best classify bilingual children who are TD and LI. With respect maximizing the difference in performance between LI and TD groups, it could be beneficial to compare the use of conceptual scores compared to language-specific scores to examine performance and change after mediation. Another possibility to compare productive differences would be to follow a transcription protocol for utterance segmentation that is more equal across English and Spanish to examine language specific productive differences in Spanish and English. Different developmental trajectories for Spanish and English have been documented (e.g. Kohnert \& Bates, 2002). Therefore, another variable to consider would be age and whether age has an effect on the language of mediation, production, or patterns of differences across language ability. A larger study might account for levels of 
language proficiency based on ratings of exposure and use to explore effects of the language of mediation and production.

The results from this study highlight the differential response in modifiability, narrative and productive measures to a short-term intervention for bilingual children with and without language impairment. Pretest to posttest changes occur regardless of the language of intervention. Children that are able to learn new strategies to improve their stories transfer these across languages. The language of story production influences the ratings that children receive on specific vocabulary use and their use of narrative macrostructure, which influences task performance. With a better understanding of the implications for the language of story production and intervention for bilingual children, results suggest that the application of dynamic assessment of narratives may be extended to bilingual populations. 


\section{Appendix A. MLE Script in English}

MLE 1 and 2

One Frog Too Many/Frog Where Are You?

-Play story back to child

-Was that a good story?

- comment on what they included, give positive feedback, mention what was missing

-Why do you think it's important to tell good stories?

- helps in school, helps with reading and writing, helps you talk better to your friends and family

-Today, we're going to talk about how to tell complete stories and the parts that make up good, complete stories. Parts: when, where, who, why, a problem and solution, and order.

-Good storytellers start by telling when and where a story happened this is called the setting.

- Helps us to understand where the people in the story live and also tells us when the story took place

- (Look at page 1 and 2) Where do you think this story took place? Where do you think the boy is?

- And when?

0 What time is it?

- How could you start this story? You want to include where and when

o Give example to help: One morning/day, the boy was in his house...

-Now that we know about the when and where of the story, let's talk about the who; like the people, animals and things that are in a story. We need to talk about who they are and what they are like.

- Let's think about the people and the animals in this story.

o Do you think the boy has a name? The big/little frog? Dog? Turtle?

o You could also tell what they look like or how they feel.

o Give example if child is struggling.

-So, let's start our story and talk about all that: who, when, and where (the setting).

"I don't know if you're talking about the boy or the dog - we need to include a name."

Next, we talk about why the characters do what they do in the story, and what happens when they do something. 
- Bring in examples of why characters are doing particular actions: Biting, looking, etc. (Causal Relationships)

So, we've talked about who's in the story, when and where the story occurs and why the characters do the things they do.

Every story also has a beginning, a middle and an end. In the beginning there is a problem, in the middle they try to solve the problem and you tell how they feel, and at the end you tell how they do solve the problem and how they feel about that.

-Do you know what a problem is?

(give example of $\$ 20$ if not).

So let's start with the problem. Let's look at a problem from the book (pushing little frog off boat.) How did they feel about the problem?

If you had a problem, (bring in child's example or use \$20 example) how would you feel? And what would you do? (look for it)

That's how you solved your problem - let's see how they solved their problem. What did they do? (they looked for little frog, little frog jumped back in window at end.) And how did they feel?

Ok, so the parts of a story we've talked about are: who, when, where, why or how they feel, the problem, and solution.

-So stories start with a problem, then the characters do something about the problem and then the problem is solved.

- Stories also include how the characters feel about the problem.

Ok, so the parts of a story we've talked about are: who, when \& where, the why, the problem, character's feelings, and a solution.

-Now, we need one more thing: order. What would happen if we told the story backwards (tell story backwards)?

We need to tell what comes first, second, next, and last so it makes sense.

- Why do you think this is important?

- First what happened? (the big frog is mad because of the little frog, then the little frog is missing and the boy has to look for the little frog)

- We can include words like first, next, and then, to describe the order of how things happened.

o (use scenery change to mark the order of the story-starts in house, they are in the forest/river, and then at the end they are back in the boy's room). 
-So tell me again what are the parts of a good story?

- The setting-when and where, the who- character information-names and what they are like, the why- why characters do what they do in the story, and the problem- how it started, what the characters did about it, and how it was resolved.

- Also, remember the order of a story is important. We need to use words like first, second, and last to help others understand the story.

-So do you think you can remember the parts of a good story.

- Setting, characters, why, problem, and the order of the story.

- Show finger cues:

-Setting: when and where

-Characters: names, what they look like

-Why- why characters do what they do in story

-Problem: what it is, actions by characters to resolve, solution

-Order: what happened first, second, last

-So, again why do you want to tell good stories?

-Okay, so now that we know all the parts of a good story, why don't you tell me this story again and try to use all the parts we talked about. 


\section{Appendix B. MLE Script in Spanish}

Mediation 1 used Frog Where Are You, Mediation 2 used One Frog Too Many.

Recuerdas cuando te enseñé éste libro? Tu dijiste [read the story back that the child told]. Fué bueno el cuento? Si ó no, porque? [tell them what parts they included/excluded in a way that they can understand].

Hoy vamos a praticar como contar cuentos completos. Cuando las personas cuentan cuentos, ellos incluyen varios aspectos necesarios para formar cuentos completos. Ellos dicen cual es el problema, qué hicieron los personajes, cómo resolvieron los problemas, qué piensan y cómo se sienten. Cuando me cuentes tu cuento, vamos a hablar de los personajes, dónde ocurrió el cuento, y cuando ocurrió.

Es importante que cuentes cuentos completos porque niños siempre se dicen cuentos, y tu lees y escribes historias en la escuela. Asi que contar cuentos completos te ayudará a communicar mejor y te ayudará a escribir y a entender mejor las historias en la escuela. Ahora, tu dime ¿porque es importante contar cuentos completos? [Help the child explain that stories are important for school and for communication].

Primero vamos a hablar de diferentes aspectos que tendras que incluir en tus cuentos. Las personas empiezan sus cuentos diciendo cómo y cuando ocurrieron los eventos. Eso nos ayuda a comprender la situación del caracter. Cuando empezamos cuentos, ¿qué es lo que tenemos que incluir? [When and where or setting]?

[Refer to page 1 of the story] ¿Cómo empieza éste cuento? [pause, wait for response, help child to respond when needed] ¿Dónde estan? [pause, wait for response] ¿Es la mañana, la tarde, ó la noche? [pause, wait for response] ¿Cómo empesarias un cuento?, incluye dónde y cuando el cuento ocurrió. [Pause, let them fill in, if they don’t, give an example]

Tambien tenemos que saber de los personajes. Cuando cuentas un cuento, tu maestra y tus amigos quieren saber quienes son los personajes y como son. Tambien tenemos que incluir que....? [informacion del personaje] Ahora vamos a pensar en los personajes. ¿A que se parecen? [pause, wait for response] ¿Tienen nombres los personajes? [pause, wait for response] Podrias decir Pedro, el niño, y la rana, que se llama Gorda, estaban mirando el regalo que recibió el niño. Podrias describirlos ó nombrarlos para dar mas informacion sobre ellos. Por ejemplo, podrias decir Gorda y de quien estubieras hablando? Si, la rana. [Can additionally use toys or puppets to describe].

En cuentos tambien tenemos que decir que ocurrió primero, segundo, y al ultimo y porque ocurren (order and causal relationships). Esto es importante porque nos ayuda a comprender en que orden ocurrieron los eventos y los motivos de los personajes.

¿Qué ocurreria si tu me dijieras el cuento empezando con la conclusion? [Help the child state that it would be difficult to know when or why things happened] Al principio del 
cuento ellos estaban,... [help child to describe], y luego [turn page] [help the child describe]. Utilizamos palabras como primero, y luego, y entonces para describir que ocurrio y porqué ocurrió el evento (order and causal relationships). [using puppets, let child act out the story and explain the order and causal relationships].

Ahora, vamos a decir un cuento que incluye todos estos aspectos. [Help child tell a story with setting, time, place, characters, temporal order and causality] [Muy bien]. En ese cuento te acordaste de incluir .......[list what they included].

Siempre recuerda de hablar de la escena (cuando y dónde), da informacion sobre los personajes, e incluye el orden y porque ocurrio los eventos. En este cuento, ¿cuando y dónde ocurrió la escena? [let child fill in, assist them], ¿qué debemos decir de los personajes? [let child fill in, assist them]; ¿qué ocurrio primero? ¿Y luego? ¿Y luego? [let child fill in, assist them]. ¿Y porqué el niño se fue buscando a todas partes? Es importante incluir esta informacion porque nos informa cuando y donde ocurrio el evento (setting), orden del cuento (order), y los motivos de los personajes (causal relationships).

Dime otra vez cuales son estos aspectos. Información sobre los personajes [let child respond, assist if necessary]; escena (cuando y donde) [let child respond, assist if necessary]; orden (temporal) [let child respond; assist if necessary]; y porque occurrio los eventos [let child respond, assist if necessary].

Ahora vamos a hablar de contar cuentos completos. Cuando las personas cuentan cuentos incluyen lo que ocurrio primero, segundo, y al ultimo. Dicen cual es el problema al principio y como se sienten los personajes sobre el problema. Y luego cuentan sobre las acciones de los personajes para resolver el problema. En la conclusion del cuento, cuentan como decidieron los personajes resolver el problema y como se sienten cuando el problema esta resuelto.

$¿$ ¿Recuerdas porque cuentos son importantes? [expand on what the child says, e.g., Es importante decir buenos cuentos porque niños siempre dicen cuentos y tu lees y escribes cuentos en la escuela. Asi que, aprender a contar cuentos completos te ayudara a comunicar mejor y te ayudara a escribir y a entender mejor las historias en la escuela]

Vamos a hablar de las partes diferentes que tienes que incluir en un cuento. Cuando personas dicen cuentos, ellos tienen que saber qué ocurrio para empezar la acción en el cuento. Esto se llama problema. ¿Qué tenemos que incluir? [Problema]. [refer to book] ¿Cómo empieza éste cuento? [child answers] [turn the page] ¿Qué piensas que causó el problema? [let them fill in] Para incluir en el problema, tu dijieras ......[pause, let them fill it in, if they don't give one example "Una tarde el niño y la rana...] [reflect back what they said—use expansion/extension as needed] [let child act out using puppets.]

Despues del problema hablamos sobre como se siente el personaje. Eso es importante porque hace el cuento mas interesante y nos ayuda a comprender a los demas eventos. ¿Qué ocurre en esta pagina? (talk about how frog is missing and how the boy might feel) 
[Problema] Si, ese es el problema. Y aqui, ¿cómo se siente el niño? (also section from book) ¿Cómo los vas a nombrar (llamar)? [then continue using the names selected]. Tienes que incluir como se sienten los personajes sobre lo que ocurrio en el cuento.

Duespes de hablar como se sienten los personajes vamos a hablar de ¿qué es lo que hacen para resolver el problema? Tambien tenemos que incluir que.....[the attempts-las acciones para resolver el problema]. [refer to the book]. ¿Qué hace el niño? [pause, let them fill in, if they don’t, give an example “Cuando vio que la rana se escapó, el niño la buscó en sus botas”].

Despues de hablar sobre lo que hace el personaje (protagonista) tenemos que decir como se resolvió el problema. ¿Qué ocurrio despues de que el niño busco la rana? [child responds that........] Muy bien; ¿cuál era el problema? [let the child restate, and help if necessary] , y ¿cómo resolvieron el problema? [again, let the child restate].

Despues de hablar del resolvimiento del problema, podemos decir como se sienten los personajes y su reación. ¿Cuál fue la conclusion del cuento? [pause, let them fill in, if they don’t, give an example "El niño y la rana eran amigos de nuevo."] ¿Piensas tu que ellos estaban contentos? ¿Cómo te sentirias tu, por qué?

Cuentos incluyen problemas, como se sienten los personajes sobre ellos, lo que hacen para resolver el problema, que ocurre, y como se sienten al ultimo. ¿Por qué es importante ésto? [Let the child answer, if not explain "Es importante porque le ayuda a mis amigos a entender mis cuentos y porque puedo leer y escribir mejor en la escuela."] Quiero que me digas un cuento sobre este libro [let child use puppets to tell the story if they choose].

¿Cómo vas a recordar de incluir todos los aspectos necesarios para decir un cuento completo? [Discuss strategies to include specific components of story and a complete episode.]

Adapted and translated from Peña et al., (2004).

Note: Examples are based on Mediation 1 from One Frog Too Many. 


\section{Appendix C. Mediated Learning Observation}

\begin{tabular}{|c|c|c|c|c|c|}
\hline & 1 & 2 & 3 & 4 & 5 \\
\hline \multicolumn{6}{|c|}{ Internal Social-Emotional (Affect) } \\
\hline Anxiety & $\begin{array}{l}\text { Calm, little to no } \\
\text { soothing } \\
\text { required }\end{array}$ & $\begin{array}{l}\text { Fidgety but can } \\
\text { be soothed }\end{array}$ & $\begin{array}{l}\text { Uncomfortable, } \\
\text { breaks needed } \\
\text { to sooth }\end{array}$ & $\begin{array}{l}\text { Distressed, } \\
\text { much soothing } \\
\text { required }\end{array}$ & $\begin{array}{l}\text { Distraught, } \\
\text { crying, cannot be } \\
\text { soothed }\end{array}$ \\
\hline Motivation & $\begin{array}{l}\text { Enthusiastic, } \\
\text { readily engages } \\
\text { in tasks }\end{array}$ & $\begin{array}{l}\text { Curious, shows } \\
\text { interest }\end{array}$ & $\begin{array}{l}\text { Ambivalent, } \\
\text { unsure about } \\
\text { tasks }\end{array}$ & $\begin{array}{l}\text { Guarded, seems } \\
\text { fearful of tasks }\end{array}$ & $\begin{array}{l}\text { Avoidant, does } \\
\text { not want to } \\
\text { engage }\end{array}$ \\
\hline \multicolumn{6}{|l|}{ Cognitive Arousal } \\
\hline Task orientation & $\begin{array}{l}\text { Completely } \\
\text { understands } \\
\text { tasks }\end{array}$ & $\begin{array}{l}\text { Mostly } \\
\text { understands } \\
\text { tasks (75\%) }\end{array}$ & $\begin{array}{l}\text { Understands } \\
\text { tasks some of } \\
\text { the time (50\%) }\end{array}$ & $\begin{array}{l}\text { Often doesn't } \\
\text { understand tasks } \\
(25 \%)\end{array}$ & $\begin{array}{l}\text { Doesn't } \\
\text { understand tasks }\end{array}$ \\
\hline Meta-cognition & $\begin{array}{l}\text { Aware of all } \\
\text { errors }\end{array}$ & $\begin{array}{l}\text { Aware of most } \\
\text { errors (75\%) }\end{array}$ & $\begin{array}{l}\text { Aware of some } \\
\text { errors (50\%) }\end{array}$ & $\begin{array}{l}\text { Unaware of most } \\
\text { errors }(25 \%)\end{array}$ & $\begin{array}{l}\text { Unaware of any } \\
\text { errors }\end{array}$ \\
\hline $\begin{array}{l}\text { Non-verbal self } \\
\text { reward }\end{array}$ & $\begin{array}{l}\text { Positive } \\
\text { response to task } \\
\text { regardless of } \\
\text { difficulty }\end{array}$ & $\begin{array}{l}\text { Positive } \\
\text { response related } \\
\text { to task difficulty }\end{array}$ & $\begin{array}{l}\text { Demonstrates } \\
\text { insecurity, } \\
\text { positive and } \\
\text { negative } \\
\text { responses } \\
\text { related to } \\
\text { difficulty }\end{array}$ & $\begin{array}{l}\text { Negative } \\
\text { response related } \\
\text { to task difficulty }\end{array}$ & $\begin{array}{l}\text { Negative } \\
\text { response } \\
\text { regardless of } \\
\text { task difficulty }\end{array}$ \\
\hline \multicolumn{6}{|c|}{ Cognitive Elaboration } \\
\hline Problem-solving & $\begin{array}{l}\text { Systematic and } \\
\text { efficient, used } \\
\text { forethought, } \\
\text { reflection }\end{array}$ & $\begin{array}{l}\text { Organized, but } \\
\text { somewhat } \\
\text { inefficient (<25\% } \\
\text { off task) }\end{array}$ & $\begin{array}{l}\text { Sketchy plan, } \\
\text { trial and error }\end{array}$ & $\begin{array}{l}\text { Disorganized, } \\
\text { haphazard plan }\end{array}$ & $\begin{array}{l}\text { No plan, } \\
\text { unsystematic } \\
\text { guessing }\end{array}$ \\
\hline Verbal mediation & $\begin{array}{l}\text { Elaborates plan } \\
\text { clearly }\end{array}$ & $\begin{array}{l}\text { Talks through } \\
\text { problem }\end{array}$ & $\begin{array}{l}\text { Talks } \\
\text { occasionally }\end{array}$ & $\begin{array}{l}\text { 1-2 utterances } \\
\text { only }\end{array}$ & $\begin{array}{l}\text { No verbal } \\
\text { mediation }\end{array}$ \\
\hline Flexibility & $\begin{array}{l}\text { Uses multiple } \\
\text { strategies readily }\end{array}$ & $\begin{array}{l}\text { Has preferred } \\
\text { strategies but } \\
\text { can change } \\
\text { when necessary }\end{array}$ & $\begin{array}{l}\text { Some evidence } \\
\text { of more than one } \\
\text { strategy and } \\
\text { occasionally } \\
\text { utilizes them }\end{array}$ & $\begin{array}{l}\text { Recognizes } \\
\text { limitations of } \\
\text { strategy, but } \\
\text { cannot see } \\
\text { alternatives }\end{array}$ & $\begin{array}{l}\text { Persists with one } \\
\text { strategy, } \\
\text { regardless of } \\
\text { outcome }\end{array}$ \\
\hline \multicolumn{6}{|c|}{ External Social-Emotional (Behavior) } \\
\hline $\begin{array}{l}\text { Responsiveness } \\
\text { to feedback }\end{array}$ & $\begin{array}{l}\text { Very positive, } \\
\text { maintains } \\
\text { enthusiasm }\end{array}$ & $\begin{array}{l}\text { Positive but } \\
\text { hesitant, requires } \\
\text { some feedback }\end{array}$ & $\begin{array}{l}\text { No response to } \\
\text { feedback }\end{array}$ & $\begin{array}{l}\text { Negative, } \\
\text { disheartened, } \\
\text { requires much } \\
\text { feedback }\end{array}$ & $\begin{array}{l}\text { Very negative, } \\
\text { rejects feedback }\end{array}$ \\
\hline Attention & $\begin{array}{l}\text { Attentive and } \\
\text { focused }\end{array}$ & $\begin{array}{l}\text { Focused, but } \\
\text { distractible at } \\
\text { times }\end{array}$ & $\begin{array}{l}\text { Distractible, but } \\
\text { can be } \\
\text { refocused, needs } \\
\text { prompting }\end{array}$ & $\begin{array}{l}\text { Distracted and } \\
\text { difficult to } \\
\text { refocus }\end{array}$ & $\begin{array}{l}\text { Distracted and } \\
\text { off task }\end{array}$ \\
\hline Compliance & Cooperative & Insecure & Hesitant & Uncooperative & Refusing \\
\hline
\end{tabular}

Copyright Elizabeth Peña, developed with Bruno Villarreal 


\section{Appendix D. Sample pretest and posttest Spanish and English transcripts from two children with and one without language impairment}

Child 119 aged 6;11 is a female with typical language development.

Pretest Bird and His Ring

English

1. (He) he saw a ring.

2. He got it.

3. And (he*) he/'s take/ing it.

4. (And) he/'s show/ing it to the bird.

5. (And the) he give it to the bird.

6. And>

7. (Now) he/'s tell/ing him that he got a ring.

8. Then he think that he give it to the bird.

9. (And th*) and he said to him to go with him to see it.

10. But they didn't find the ring.

11. And they/'re look/ing for it.

12. (And) they/'re look/ing for it here too.

13. (And) here they/'re look/ing for it.

14. (And) they (fin*) found it.

15. (And) he got it.

\section{Child 119}

Pretest Two Friends

Spanish with the English translation below each line

1. El perro +le está diciendo al gato si pueden hacer amigo/s.

\{The dog is saying to the cat if they can make friends.\}

2. Aquí el perro +se estaba lamiendo.

\{Here the dog is licking himself.\}

3. Y el gato (está está) +lo está mirando.

\{And the cat is looking at him.\}

4. Y el perrito toda vez está dormiendo.

\{And the doggie is all the time still sleeping.\}

5. Y el gato está| triste.

\{And the cat is sad.\}

6. Y todavía aquí esta el perro dormido.

\{And still here is the dog sleeping\}.

7. (Y) y el gato mira al perro.

\{And the cat looks at the dog.\}

8. (Y) aquí el perro está dormido.

\{And here the dog is sleeping.\} 
9. Aquí +se despertó el perro.

\{Here the dog wakes up.\}

10. Y dijo|decir "¿donde está el gato"?

\{And says "Where is the cat"?\}

11. (Y) no +lo encuentra.

\{And (he) doesn't find him\} .

12. +Lo fue a buscar.

\{He went to look.\}

13. Y encontró (a una) a la lagartija.'

\{And (he) found the lizard (dimunitive).

14. Y +le preguntó si sabe donde está el gato.

\{And he asked him if he knew where the cat was.\}

15. Y dijo la lagartija que no sabía.

\{And the lizard said that (he) didn't know.\}

16. Y el perro (le dijo em*) encontró a un armadillo.

\{And the dog (said um) found an armadillo.\}

17. Y +le preguntó si sabe donde estaba el gato.

\{And he asked him if he knew where the cat was.\}

18. Y +le dijo que no sabía|saber.

\{And he said that he didn't know.

19. (Y) encontró unos pez/s.

\{And (he) met some fish .

20. $(\mathrm{Y}+$ les pre* $\mathrm{y})+$ se +les preguntó.

\{And they were asking each other.\}

21. (Y) dijo que no sabían.

\{And (he) said that (they) didn't know.\}

22. (Y) el perro vío una cola aquí.

\{And the dog saw a tail here.\}

23. (Y) era (el) el gato.

\{And (it) was the cat.\}

Child 119

Posttest Two Friends

English

1. There was one day a dog and a cat.

2. They were friend/s.

3. (Then they the) next the dog went to sleep.

4. And the cat ( $\mathrm{s}^{*} \mathrm{um}$ ) want/ed to do a trick to him.

5. And the dog still sleep/ing.

6. And the cat is sad.

7. And the dog sleep/ing .

8. Then the cat went to hide from the dog.

9. And the dog still sleep/ing.

10. And then (do*) dog woke up. 
11. Then (he) he said, "Where is the cat"?

12. And then he went to look (for him) for the cat.

13. Then he ask/ed the lizard if he had seen that cat.

14. And he said, "no".

15. Then he ask/ed the armadillo.

16. Then he said, "no".

17. He ask/ed the fish.

18. And the fish said, "no".

19. Then he saw the tail.

20. And it was the cat.

21. The end.

Child 119

Bird and His Ring Posttest

Spanish

1. Había una vez un lobo que halló un anillo.

\{Once upon a time there was a wolf who searched for a ring.\}

2. $\mathrm{Y}+$ se $\left(\mathrm{l}^{*}\right)+$ lo quedó.

\{And he left it.

3. $Y+$ lo fue a enseñar a pájaro.

\{And (he) went to show to bird.

4. Y +le dijo que +se +lo quedaba.

\{And he said that he left it himself\}.

5. C. +le dejó a decir (a la*) a lagartija si hay un anillo.

$\{$ he let to say to the lizard (dimunitive) if there was a ring .

6. (Y aquí) dijo (que está arriba de del $n^{*}$ ) que estaba arriba donde estaba el pájaro.

\{And here said (that it was up the) that it was up where the bird was.

7. Y luego (pá*) cuando fue a ver+lo (el) el pájaro dijo que +se +le había caído.

\{And then when (he) went to see it the bird said that it had fallen.\}

8. (Y) aquí +le está preguntando si ha visto el anillo.

\{and here (he) was asking if (he) had seen the nest.

9. (Y aquí) +le está preguntando (a al al al) a la abeja si a +lo había visto.

\{And here (he) was asking the bee if he had seen it.

10. (Y) +lo dijo que no.

\{And he told him no.

11. (Y dijo) +le pregunto (la) a la lagartija, "Has visto el anillo" ?

$\{($ And said) he asked the lizard "Have (you) seen the ring?" $\}$

12. (Y) dijo "no" .

\{And (he) said "No".\}

13. (Y aquí) hallaron el anillo.

\{And here (he) searched for the ring.

14. (Y aquí) +lo agarró el (anillo) anillo.

\{And here (he) grabbed the ring.\} 
Child 178 is a 7;0 male with language impairment.

Pretest Two Friends

English

1. There/'s a dog and a cat.

2. They/'re friend/s.

3. Happy friend/s and good friend/s.

4. The dog snore/3s.

5. and the cat (um um) look.

6. The dog (um) was sleep/ing and snore/ing.

7. and the cat was sad.

8. (and) the cat walk away.

9. (and) the dog still sleep/ing.

10. (and) the dog he/'s sleepwalk/ing.

11. (and) the dog where is cat.

12. (and) the dog run to find cat.

13. (and) the dog ask/ed a dragon.

14. (and) the dog ask/ed an armadillo.

15. (and) then a whale come on the fish.

16. (and) (um) the dog follow that tail.

17. (and) find cat.

18. the end.

Child 178

Pretest Bird and His Ring

Spanish

1. Ahh, una esto?

\{Ahh, one of those.

2. Ah un garcianito.

\{Ah, a stork (dimuniuitive). $\}$

3. (La garcianita ah) el garcianito agarra (ah) un diamond.

\{(The storky ah (feminine) the storky (masculine) grabs a diamond.\}

4. Y (la Mejor el pato) Pato llevó la diamonte a la pajarito nest.

\{And (better the duck) Duck brought the diamond to the birdy's nest.\}

5. Y (an) +la dejo a la (an a la) pajarito nest.

\{And (he) left it at the bird's nest.\}

6. (Y) el pato dició al (xxx) ¿̇a donde está la diamond?

\{And the duck said to (unintelligible) "Where is the diamond"?\}

7. Y (an) dónde está la diamond?

\{And where is the diamond?\}.

8. ¡Está aquí!

\{It's here!

9. Ah, no está. 


\author{
\{Ah, (it's) not here. $\}$ \\ 10. (An) iguros! \\ \{ A guros (invented word). \\ 11. Si, Guros. \\ \{Yes, guros . \\ 12. Vés|ver sí (an) el diamond no? \\ \{You see yes ) the diamond no?\} \\ 13. (Um), igusano/s! \\ \{Um, worms. \\ 14. Gusano +me viste mi diamond? \\ \{Worm, you saw me my diamond?\} \\ 15. ¡No! \\ \{No.\} \\ 16. ¿Dónde está el gusano? \\ \{Where is the worm?\} \\ 17. ¿Dónde está mi diamond? \\ \{Where is my diamond?\} \\ 18. ¡Aquí está! \\ \{Here it is.\} \\ 19. ¡The End! \\ Child 178 \\ Posttest Bird and His Ring \\ English
}

1. The goose (um um) found the ring.

2. and the goose (put) put it (uh) somewhere so he know where he can find it.

3. (um) the goose find a place where nobody can find the ring.

4. and the goose (le*) left the bird with the ring.

5. (and) the goose look out where she putted the ring.

6. (and) he ask (um) lizard.

7. (and) the goose (um) talk with the bird.

8. (and) the bird "aaaaah".

9. (and) the goose was sad.

10. (and) the goose (um) tell the sunflower where is she ring.

11. (and) the goose said (um) "blaah".

12. (and) where is she ring.

13. (and and $\mathrm{sh}^{*}$ ) the goose remember/ed where the ring is.

14. (and) she finally found she ring.

15. (and) it was all the time that look \{and look the ring (uh) the goose it was on the bird nest. 
Child 178

Posttest Two Friends

Spanish

1. la gato y la perro están despiertos.

\{The cat and the dog are awake.\}

2. la perro está dormido.

\{The dog is sleeping.\}

3. y la gato (um) está (es a) despierto.

\{And the cat is awake.\}

4. (y) la perro (um) caminó al reves.

\{And the dog walked backwards.\}

5. (y) la gato estaba muy triste.

\{And the cat was very sad.\}

6. (y) la gato (um) caminó solo.

\{And the cat walked alone.\}

7. (y) la perro caminó solo tambien.

\{And the dog also walked alone.

8. (y) la perro (um) +se despertó.

= says se sperto

\{And the dog (um) woke up.\}

9. (y) dijo "donde está el gato".

\{And said "where is the cat"?

10. (y) +se corrió.

\{And (he) ran himself.\}

11. (la perro) la perro (um) dijo la dragon "donde está el gato".

\{The dog said the dragon "where is the cat"?\}

12. (perro la perro dijo el perro) el perro dijo "pelota, en donde está gato"?

\{(dog the dog said the dog) the dog said "ball, where is cat"?\}

13. la perro (um) caminó a la río.

\{The dog walked to the river.\}

14. y perro corrió.

\{And dog ran.\}

15. (y um) la perro habia un cola.

\{And the dog had a tail.\}

16. (y) la perro está feliz porque (um) buscó la gato.

\{And the dog is happy because (um) looked the cat.\}

17. The end. 


\section{References}

Anderson, R.C., Reynolds, R.E., Schallert, D.L. \& Goetz, E.T. (1977). Frameworks for comprehending discourse. American Educational Research Journal, 14, 367-381.

August, D, \& Shanahan, T. (2006). Developing literacy in second-language learners, Report of the National Literacy Panel on Language Minority and Youth. Mahwah, NJ; Erlbaum.

Bamberg, M.G.W. (1987). The acquisition of narratives. Berlin: Mouton de Gruyter.

Barclay, L. K. (1983). Using Spanish as the language of instruction with MexicanAmericanHead Start children: A reevaluation using meta-analysis. Perceptual and Motor Skills, 56, 359-366.

Bartlett, F.C. (1932). Remembering. Cambridge: Cambridge University Press.

Bedore, L.M. (2004). Morphosyntactic development. In In B. Goldstein (Ed.), Bilingual language development and disorders in Spanish-English speakers (pp. 163-185), Baltimore, Maryland, US: Paul H. Brookes Publishing.

Bedore, L.M., Fiestas, C.E., Peña, E.D., \& Nagy, V.J. (2006). Cross-language comparisons of maze use in Spanish and English in functionally monolingual and bilingual children. Bilingualism, Language and Cognition, 9, 233-247.

Bedore, L.M., Peña, E.D., Garcia, M., \& Cortez, C. (2005). Conceptual versus monolingual scoring: When does it make a difference? Language, Speech, and Hearing Services in Schools, 36, 188-200.

Berman, R., \& Slobin, D. (1994). Relating events in narrative: A crosslinguistic developmental study. Hillsdale, NJ: Erlbaum. 
Bialystock, E. (2001). Bilingualism in development: Language, literacy and cognition. Cambridge: Cambridge University Press.

Brewer, W. F., \& Dupree, D. A. (1983). Use of plan schemata in the recall and recognition of goal directed actions. Journal of Experimental Psychology 9, 117129.

Botting, N. (2002). Narrative as a tool for assessing linguistic and pragmatic impairment. Child Language Teaching and Therapy, 18, 1-21.

Boudreau, D. (2008). Narrative abilities: Advances in research and implications for clinical practice. Topics in Language Disorders, 28, 99-114.

Bracken, B. A. \& McCallum, R. S. (1998). Universal Nonverbal Intelligence Test. Illinois: Riverside Publishing.

Brown, R. (1973). A first language: The early stages. Cambridge, MA: Harvard University Press.

Bruner, J. (1985). Narrative and paradigmatic modes of thought. In E. Eisner (Ed.), Learning, and teaching and the ways of knowing, (pp. 97-115). Chicago: University of Chicago Press.

Bruner, J. (1986). Actual minds, possible worlds. Cambride: Harvard University Press.

Cazden, C.B. (2001). Classroom discourse: The language of teaching and learning. Portsmouth, NH: Heinemann.

Cirrin, F.M. \& Gillam, R.B. (2008). Language intervention practices for school-age children with spoken language disorders: A systematic review. Language, Speech, and Hearing Services in Schools, 39, 110-137.

Cummins, J. (1991). Interdependence of first-and second-language proficiency in 
bilingual children. In E. Bialystock, Ed., Language Processing in Bilingual Children, (pp 70-89). Cambridge: Cambridge University Press.

Dickinson, D., \& Tabors, P. (Eds.). (2001). Beginning literacy with language: Young children learning at home and school. Baltimore: Brookes.

Duchan, J. (1986). Learning to describe events. Topics in Language Disorders, 6, 27-36.

Eisenberg, A. R. (1985). Learning to describe past events in conversation. Discourse Processes, 8, 177-204.

Fiestas, C. E., \& Peña, E. D. (2004). Narrative discourse in bilingual children: Language and task effects. Language, Speech, and Hearing Services in Schools, 35, 155-168.

Fiestas, C. E., Peña, E., Gorman, B., \& Gillam, R. B. (2003, November). Goal planning devices and internal states in bilingual children's narratives. Student technical presentation at the annual meeting of the American Speech-Language and Hearing Association, Chicago Illinois.

Feuerstein, R. (1980). Instrumental enrichment: An intervention program for cognitive modifiability. Baltimore: University Park Press.

Fivush, R. (1991). The social construction of personal narratives. Merrill-Palmer Quarterly, 37, 59-81.

Gillam, R. B. \& Carlile, R. M. (1997). Oral reading and story retelling of students with specific language impairment. Language, Speech, and Hearing Services in Schools, 28, 30-42.

Gillam, R. B., McFadden, T. U., \& van Kleeck, A. (1995). Improving narrative abilities: Whole language and language skills approaches. In M. Fey, J. Windsor \& S. 
F. Warren (Eds.) Language Intervention: Preschool through the elementary years. Baltimore: Brookes Publishing Company.

Grosjean, F. (1989). Neurolinguists beware! The bilingual is not two monolinguals in one. Brain and Language, 36, 3-15.

Grosjean, F. (1997). Processing mixed language: Issues, findings and models. In A.

M. B. de Groot \& J. F. Kroll (Eds.), Tutorials in Bilingualism: Psycholinguistic perspectives. (pp. 225-254). Mahwah, New Jersey: Lawrence Erlbaum Associates.

Grosjean, F. (2001). The bilingual's language modes. In J.L. Nichol (Ed.) One mind, two languages: Bilingual language processing (pp. 1-23). Mahwah, NJ: Lawrence Erlbaum Associates.

Guo, L., Tomblin, B. J., Samelson, V. (2008). Speech disruptions in the narratives of English-speaking children with specific-language impairment. Journal of Speech, Language and Hearing Research, 51, 722-738.

Gutierrez-Clellen, V.F. (1999). Language choice in intervention with bilingual children. American Journal of Speech-Language Pathology, 8, 291-302.

Gutierrez-Clellen, V.F. (2002). Narratives in two languages: Assessing performance of bilingual children. Linguistics and Education, 13, 175-197.

Gutierrez-Clellen, V.F. (2004). Narrative development and disorders in bilingual children. In B. Goldstein (Ed.), Bilingual language development and disorders in Spanish-English speakers (pp. 235-256), Baltimore, Maryland, US: Paul H. Brookes Publishing.

Gutierrez-Clellen, V. F. \& Kreiter, J. (2003). Understanding child bilingual 
acquisition using parent and teacher reports. Applied Psycholinguistics, 24, 267-288.

Gutierrez-Clellen, V. F. \& Peña. E. (2001). Dynamic assessment of diverse children:

A tutorial. Language, Speech, and Hearing Services in Schools, 32, 221-224.

Gutierrez-Clellen, V. F., Peña, E. D., \& Quinn, R. (1995). Accomodating cultural differences in narrative style: A multicultural perspective. Topics in Language Disorders, 15, 54-67.

Gutierrez-Clellen, V.F., \& Quinn, R. (1993). Assessing narratives in diverse cultural/linguistic populations: Clinical implications. Language, Speech and Hearing Services in Schools, 24, 2-9.

Gutierrez-Clellen, V. F., Restrepo, M. A., Bedore, L., Peña, E., \& Anderson, R. (2000). Language sample analysis in Spanish-speaking children: Methodological considerations. Language, Speech, and Hearing Services in Schools, 31, 88-98.

Haberland, K., Berian, C. \& Sanderson, J. (1980). The episode schema in story processing. Journal of Verbal Learning and Verbal Behavior. 19, 635-650.

Hayward, D.V., Gillam, R.B., \& Lien, P. (2007). Retelling a script-based story: Do children with and without language impairments focus on script and story elements?, American Journal of Speech-Language Pathology, 16, 235-245.

Hickson, J., \& Skuy, M. (1990). Creativity and cognitive modifiability in gifted disadvantaged pupils: A promising alliance. School Psychology International, $11,295-301$.

Hudson, (1993). Reminiscing with mother and others: Autobiographical memory in 
mother-child conversation. Journal of Narrative and Life History. 3, 1-32.

Hughes, D., McGillivray, L., \& Schmidek, M. (1997). Guide to narrative language: Procedures for assessment. Eau Claire, WI: Thinking Publications.

Juarez, M. (1983). Assessment and treatment of minority language-handicapped children: The role of the monolingual speech-language pathologist. Topics in Language Disorders 3, 57-65.

Justice, L. M., Bowles, R. P., Kaderavek, J. N. Ukrainetz, T. A., Eisenberg, S. L., \& Gillam, R. B. (2006). The Index of Narrative Microstructure: A Clinical Tool for Analyzing School-Age Children's Narrative Performances. American Journal of Speech-Language Pathology, 15, 177-191.

Kayser, H. (1995). Intervention with children from linguistically and culturally diverse backgrounds. In M. E. Fey, J. Windsor, \& S. F. Warren (Eds.) Language intervention: Preschool through the elementary years (pp. 315-332). Baltimore: Paul H. Brookes.

Kayser, H. (1998). Assessment and intervention resource for Hispanic children. San Diego: Singular Publishing Group.

Kester, E. S., Peña, E. D., Gillam, R. B. (2001). Outcomes of dynamic assessment with culturally and linguistically diverse students: A comparison of three teaching methods within a test-teach-retest framework. Journal of Cognitive Education and Psychology, 2 (1), 42 - 59.

Kiernan, B., \& Swisher, L. (1990). The initial learning of novel English words: Two 
single-subject experiments with minority-language children. Journal of Speech and Hearing Research, 33, 707-716.

Kintsch, W. \& Greene, E. (1978). The role of culture-specific schemata in the comprehension and recall of stories. Discourse Processes, 1, 1-13.

Kintsch, W. \& van Kijk, T.A. (1978). Toward a model of text comprehension and production. Psychological Review, 85, 363-394.

Kohnert, K. (2008). Language disorders in bilingual children and adults. San Diego: Plural Publishing.

Kohnert, K. \& Bates, E. (2002). Balancing bilinguals II: Lexical comprehension and Cognitive processing in children learning Spanish and English. Journal of Speech, Language and Hearing Research, 45, 347-359.

Kohnert, K., Bates, E., \& Hernandez, A.E. (1999). Balancing bilinguals: Lexicalsemantic production and cognitive processing in children learning Spanish and English. Journal of Speech, Language and Hearing Research, 42, 14001413.

Kohnert, K., \& Derr, A. (2004). Language intervention with bilingual children. In B. Goldstein (Ed.), Bilingual language development and disorders in SpanishEnglish speakers (pp. 311-338), Baltimore, Maryland: Paul H. Brookes Publishing.

Kozulin, A. (2002). Sociocultural theory and the mediated learning experience. School Psychology International, 23, 7-35.

Krashen, S. (1985). The input hypothesis: Issues and implications. London: Longman. 
Kupersmitt, J. (2004). Form-function relations in Spanish narratives: A comparative study of bilingual and monolingual speakers. In S. Stromqvist \& L. Verhoeven (Eds). Relating events in narrative volume 2: Typological and contextual perspectives. Mahwah, N.J.: Lawrence Erlbaum Associates.

Laing, S.P. \& Kamhi, A. (2003). Alternative assessment of language and literacy in culturally and linguistically diverse populations. Language, Speech and Hearning Services in Schools, 34, 44-55. .

Lidz, C. S. (1991). Practicioner's guide to dynamic assessment. New York: Guilford Press.

Liles, B. Z. (1985a). Cohesion in the narratives of normal and language-disordered children. Journal of Speech and Hearing Research, 28, 129-133.

Liles, B. Z. (1985b). Production and comprehension of narrative discourse in normal and language- disordered children. Journal of Communication Disorders, 18, 409-427.

Liles, B. Z. (1993). Narrative discourse in children with language disorders and children with normal language: A critical review of the literature. Journal of Speech and Hearing Research, 36, 868-883.

Lindsey, K., Manis, F. \& Bailey, C. (2003). Prediction of first-grade reading in Spanish-speaking English-language learners. Journal of Educational Psychology, 95, 482-494.

Loban, W. (1976). Language development: Kindergarten through grade twelve. Urbana, IL: National Council of Teachers of English.

MacWhinney, B. (1987). Applying the competition model to bilingualism. Applied 
Psycholinguistics, 8, 315-327.

MacWhinney, B. (1992). Transfer and competition in second language learning. In R.

J. Harris (Ed.) Cognitive processes in bilinguals (pp. 371-390). Amsterdam, The Netherlands: North Holland.

MacWhinney, B. (1997). Second language acquisition and the competition model. In A.M.B. de Groot \& J.F. Kroll, (Eds.), Tutorials in bilingualism, (pp. 113142). Mahwah, NJ: Earlbaum.

MacWhinney, B. (2005). A unified model of language acquisition. In A.M.B. de Groot \& J.F. Kroll (Eds.) , Handbook of bilingualism: Psycholinguistic approaches. New York, New York, US: Oxford University Press.

Mandler, J. (1978). A code in the node: The use of story schema in retrieval. Discourse Processes, 1, 14-35.

Mandler, J. M., (1983). Representation. In P. Mussen (Ed.), Handbook of child psychology: Cognitive development. New York: Wiley.

Mandler, J. M. \& Johnson, N. S (1977). Remembrance of things parsed: story structure and recall. Cognitive Psychology 9, 111-151.

Mandler, J. M., Scribner, S., Cole, M., \& Deforest, M. (1980). Cross-cultural invariance in story recall. Child development, 51, 19-26.

Manis, F., Lindsey, K., \& Bailey, C. (2004). Development of reading in grades K-2 in Spanish-speaking English-language learners. Learning Disabilities Research and Practice, 19, 214-224.

Mayer, M. (1969). Frog, where are you? New York: Dial Books for Young Readers. Mayer, M. \& Mayer, M. (1975). One frog too many. New York: Dial Books for 
Young Readers

Marian, V. \& Kaushanskaya, M. (2004). Self-construal and emotion in bicultural bilinguals. Journal of Memory and Language, 51, 190-201.

Matsuyama, U.K. (1983). Can story grammar speak Japanese? The Reading Teacher, 36, 666-669.

McFadden, T. U. \& Gillam, R. B. (1996). An examination of the quality of narratives produced by children with language disorders. Language, Speech, and Hearing Disorders in Schools, 27, 48-56.

McCabe, A. (1997). Developmental and cross-cultural aspects of children’s narration. In M. Bamberg (Ed.) Narrative development: Six approaches (pp. 137-174). Mahwah, NJ: Lawrence Erlbaum Associates.

McCabe, A. \& Bliss, L.S. (2003). Patterns of narrative discourse: A multicultural life span approach. (pp.73-90). Boston, MA: Allyn and Bacon.

Melzi, G. (2002). Cultural variations in the construction of personal narratives: Central-American and European-American mother's elicitation style. Discourse Processes, 30, 153-177.

Merritt, D., \& Liles, B. (1987). Story grammar ability in children with and without language disorders: Story generation, story retelling and story comprehension. Journal of Speech and Hearing Research, 30, 539-552.

Miller, J., \& Chapman, R.S. (1981). The relation between age and mean length of utterance in morphemes. Journal of Speech and Hearing Research, 24, 154161. 
Miller, J., \& Chapman, R.S. (2002). SALT for Windows-Research version 7.0. Language Analysis Laboratory, Waisman Center, University of WisconsinMadison, Madison, WI.

Miller, J. \& Iglesias, A. (2002-2004). Systematic analysis of English and Spanish language transcripts. Language Analysis Laboratory, Waisman Center, University of Wisconsin-Madison, Madison, WI.

Miller, J., Iglesias, A., Heilman, J., Fabiano, L., Nockerts, A., \& Francis, D. (2006). Oral language and reading in bilingual children. Learning Disabilities Research and Practice, 21, 30-43.

Miller, L. (2000a). Bird and his ring. Austin, TX: Neon Rose Productions

Miller, L. (2000b). Two Friends. Austin, TX: Neon Rose Productions.

Miller, L., Gillam, R. B., \& Peña, E. D. (2001). Dynamic assessment and intervention: Improving children's narrative skills. Austin, TX: Pro-Ed

Minami, M. (2002). Culture specific language styles: The development of oral narrative and literacy. Clevedon, England: Multilingual Matters.

Minami, M. \& McCabe, A. (1995). Rice balls and bear hunts: Japanese and North American family narrative patterns. Journal of Child Language, 22, 423-445.

Muñoz, M. L., Gillam, R. B., Peña, E. D., \& Gulley-Faehnle, A. (2003). Measures of language development in fictional narratives of Latino children. Language, Speech, and Hearing Services in Schools, 34, 332-342.

Nelson, K. (1993). Events, narratives, memory: What develops. In C. A. Nelson (Ed.), 
Memory and affect in development (Vol. 26, pp. 1-24). Hillsdale, NJ: Lawrence Erlbaum Associates, Inc.

Nelson, K., Hampson, J., \& Kessler, L. (1993). Nouns in early lexicons: evidence, explanations and implications. Child Language, 20, 61-84.

Nelson, K., \& Nelson, A. P. (1990). Category production in response to script and category cues by kindergarten and second-grade children. Journal of Applied Developmental Psychology, 11, 431-446.

Newman, R. M. \& McGregor, K. K. (2006). Teachers and laypersons discern quality differences between narratives produced by children with and without SLI. Journal of Speech, Language, and Hearing Research, 49, 1022-1036.

Norbury, C. F. \& Bishop, D. V. M. (2003). Narrative skills of children with communication impairments. International Journal of Language and Communication Disorders, 38, 287-313.

Ortiz, A. A. \& Garcia, S. B. (1990). Using language assessment data for language and instructional planning for exceptional bilingual students. In A. Carasquillo and B. Baecher (Eds.), Teaching the bilingual special education student (pp. 24-47). Norwood, NJ: Ablex.

Oller, D.K., \& Pearson, B.Z. (2002). Assessing the effects of bilingualism: A background. In D.K. Oller \& R.E. Eilers (Eds.), Language and literacy in bilingual children (pp. 3-21). Clevedon, UK: Multilingual Matters.

Patterson, J.L. \& Pearson, B.Z. (2004). Bilingual lexical development. In B. 
Goldstein (Ed.), Bilingual language development and disorders in SpanishEnglish speakers (pp. 77-104), Baltimore, Maryland: Paul H. Brookes Publishing.

Pearson, B. (2002). Narrative competence among monolingual and bilingual schoolchildren in Miami. In D. Oller \& R. Eilers (Eds.), Language and literacy in bilingual children. Clevedon, UK: Multilingual Matters.

Pearson, B.Z., \& Fernandez, S.C. (1994). Measuring bilingual children’s receptive vocabularies. Child Development, 63, 1012-1221.

Pearson, B.Z., Fernandez, S.C., Lewedeg, V. \& Oller, D.K. (1997). The relation of input factors to lexical learning by bilingual infants. Applied Psycholinguistics, 18, 4158.

Peña, E. D. (1996). Dynamic Assessment: The model and its language applications. In K. Cole, P. Dale, \& D. Thal (Eds.) Assessment of Communication and Language. Baltimore, MD: Brookes.

Peña, E., Gillam, R., Malek, M, Ruiz-Felter, R., Resendiz, M., Fiestas, C. E. \& Sabel, T. (2006). Dynamic assessment of school-age children's narrative ability: An experimental investigation of classification accuracy. Journal of Speech, Language and Hearing Research, 49, 1037-1057.

Peña, E., Iglesias, A., \& Lidz, C.S. (2001). Reducing test bias through dynamic assessment of children's word learning ability. American Journal of SpeechLanguage Pathology, 10, 138-154.

Peña, E.D., \& Kester, E.S., (2004). Semantic development in Spanish-English 
bilinguals. In In B. Goldstein (Ed.), Bilingual language development and disorders in Spanish-English speakers (pp. 105-128), Baltimore, Maryland: Paul H. Brookes Publishing.

Peña, E., Quinn, R., \& Iglesias, A. (1992). The application of dynamic methods to language assessment: A non-biased procedure. Journal of Special Education, 26, 269-280.

Peña, E.D., Resendiz, M. \& Gillam, R.B. (2007). The role of clinical judgements of modifiability in the diagnosis of language impairment. Advances in SpeechLanguage Pathology, 9, 332-345.

Perez, C. (1992). Clinician's perceptions of children's oral personal narratives. Unpublished master's thesis, University of Massachussetts, Boston.

Perez, C. \& Tager-Flusberg, H. (1998). Clinician's perceptions of children's oral personal narratives. Narrative Inquiry, 8, 181-201.

Perozzi, J. A. (1985). A pilot study of language facilitation for bilingual, languagehandicapped children: Theoretical and intervention implications. Journal of Speech and Hearing Disorders, 50, 403-406.

Perozzi, J. A., \& Chavez-Sanchez, M. L. (1992). The effect of instruction in first language on

receptive acquisition of second language for bilingual children with language delay. Language, Speech, and Hearing Services in Schools, 23, 348-352.

Peterson, C. \& McCabe, A. (1994). A social interactionist account of developing decontextualized narrative skill. Developmental Psychology, 30, 937-948.

Pollard-Durodola, S. D., Mathes, P. G.; Vaughn, S., Cardenas-Hagan, E, Linan- 
Thompson, S. (2006). The Role of Oracy in Developing Comprehension in Spanish-Speaking English Language Learners. Topics in Language Disorders, 26, 365-384.

Porter, R. P. (1996). Forked tongue: The politics of bilingual education $\left(2^{\text {nd }}\right.$ ed.). New Jersey:Transaction Publishers.

Proctor, C., Carlo, M., August, D., \& Snow, C. (2005). Native Spanish-speaking children reading in English: Toward a model of comprehension. Journal of Educational Psychology, 97, 246-256.

Restrepo, M.A. \& Kruth, K. (2000). Grammatical characteristics of a Spanish-English bilingual child with specific-language impairment. Communication Disorders Quarterly, 21, 66-76.

Riggenbach, H. (1991). Toward and understanding of fluency: A microanalysis of nonnative speaker conversations. Discourse Processes, 14, 423-441.

Ripich, D. N. \& Griffith, P. L. (1988). Narrative abilities of children with learning disabilities and nondisabled children: Story structure, cohesion and propositions. Journal of Learning Disabilities, 21, 165-173.

Rodino, A. M., Gimbert, C., Perez, C., Craddock-Willis, K., \& McCabe, A. (1991). Getting your point across: Contrastive sequencing in low-income AfricanAmerican and Latino children's personal narratives. Paper presented at Boston Univeristy Language Conference, Boston, MA.

Rogoff, B. (1990). Apprenticeship in thinking: Cognitive development in social context. New York: Oxford University Press.

Rumelhart, D.E. (1975). Notes on a schema for stories. In D.G. Bobrow \& A. Collins 
(Eds.), Representation and understanding: Studies in cognitive science. New York: Academic Press.

Seliger, H. (1989). Semantic transfer constraints on the production of English passives by Hebrew-English bilinguals. In H. Dechert \& M. Raupach (Eds.), Transfer in language production (pp. 210-234). Norwood, NJ: Ablex.

Silliman, E.R., Huntley Bahr, R., Brea, M.R., Hnath-Chisolm, T., \& Mahecha, N.R. (2002). Spanish and English proficiency in the lintuistic encoding of mental states in narrative retellings. Linguistics and Education, 13, 199-234.

Silva, M.J., \& McCabe, A. (1996). Vignettes of the continuous and family ties: Some Latino American traditions. In A. McCabe (Ed.), Chameleon readers: Teaching children to appreciate all kinds of good stories (pp. 116-136). New York: McGraw-Hill.

Soter, A.O. (1988). The second language learner and cultural transfer in narration. In Purves, A.C. (Ed.) Writing across languages and cultures, Newbury Park, CA: Sage Publications.

Stavans, A. (2003). Bilinguals as narrators: A comparison of bilingual and monolingual Hebrew and English narratives. Narrative Inquiry, 13, 151-191.

Stein, N.L. \& Glenn, C.G. (1979). An analysis of story comprehension in elementary school children. In R.O. Freedle (Ed.). New directions in discourse processing: Advances in discourse processes. Norwood, N.J.: Ablex.

Sternberg, R. J., Grigorenko, E. L., Ngorosho, D., Tantufuye, E., Mbise, A., Nokes, C., Jukes, M., Bundy, D. A. (2002). Assessing intellectual potential in rural Tanzanian school children. Intelligence, 30, 141-162. 
Stockman, I. (1996). The promises and pitfalls of language sample analysis as an assessment tool for linguistic minority children. Language, Speech, and Hearing Services in Schools, 27, 355-372.

Stromqvist, S. \& Verhoeven, L. (2004). Relating events in narrative Vol.2:

Typological and contextual perspepctives. Mahwah, N.J.: Lawrence Erlbaum Associates.

Stubbe Kester, E., Peña, E.D., \& Gillam, R.B. (2001). Outcomes of dynamic assessment with culturally and linguistically diverse students: A comparison of three teaching methods within a test-teach-retest framework. Journal of Cognitive Education and Psychology, 2, 42-56.

Tannen, D. (1980). A comparative analysis of oral narrative strategies: Athenian Greek and American English. In W. Chafe (Ed.) The Pear Stories: Cognitive, cultural and linguistic aspects of narrative production. Advances in Discourse Processes Vol. 2. Norwood, NJ: Ablex.

Thordardottir, E. T., Weismer, S. E., \& Smith, M. E. (1997). Vocabulary learning in bilingual and monolingual clinical intervention. Child Language Teaching and Therapy, 13, 215-227.

Thornkyke, P.W. (1977). Cognitive structures in comprehension and memory of narrative discourse. Cognitive psychology, 9, 77-110.

Tomasello, M. (1999). Cultural origins of human cognition. Cambridge, MA: Harvard University Press.

Tomasello, M. (2003). Constructing a language. Cambridge MA: Harvard University Press. 
Toppelburg, C., Snow, C.E., \& Tager-Flusberg, H. (1999). Severe developmental disorders and bilingualism. Journal of the American Academy of Child \& Adolescent Psychiatry, 38, 1197-1199.

Trevise, A. \& Remy, P. (1986). Second language acquisition by adult immigrants: Exemplified methodology. Studies in Second Language Acquisition, 8, 265275.

Uccelli, P. \& Paez, M. M. (2007). Narrative and vocabulary development of bilingual children from kindergarten to first grade: Developmental changes and associations among English and Spanish skills.Language, Speech, and Hearing Services in Schools, 38, 225-236

Ukrainetz, T. A., Harpell, S., Walsh, C., \& Coyle, C. (2000). A preliminary investigation of dynamic assessment with native American kindergartners. Language, Speech, and Hearing Services in Schools, 31, $142-154$.

van Dijk, T. \& Kintsch, W. (1983). Strategies for discourse comprehension. New York: Academic Press.

Vygotsky, L. (1978). Mind in society. Cambridge, MA: Harvard University Press.

Vygotsky, L. S. (1986). Thought and language. Cambridge, MA: MIT Press.

Wang, Q., \& Leichtman, M.D. (2000). Same beginnings, different stories: A comparison of American and Chinese children's narratives. Child Development, 71, 13291346.

Westby, C., Moore, C., \& Roman, R. (2002). Reinventing the enemy’s language: Developing narratives in Native-American Children. Linguistics and Education, 13, 235-269. 
Whorf, B.L. (1956). Language, thought and reality. Cambridge, MA: MIT Press.

Yates, J. R. (1988). Demography as it affects special education. In A. Ortiz \& B. Ramirez (Eds.) Schools and the culturally diverse: Promising practices and future directions (pp. 234-275). Reston, VA: Council for Exceptional Children. 


\section{Vita}

Christine Eve Fiestas was born in Rochester, New York on October 22, 1965 to Martha Jane and Edward John Wilbur. Christine graduated from Burlington High School in Burlington, Vermont. She received her Bachelor of Arts in Biochemistry with a minor in French, and her Master of Arts in Speech-Language Pathology from the University of Texas at Austin in 1987 and 2001 respectively. Prior to graduate studies, she worked at the Maine Medical Center Research Institute as a Research Associate in the field of Neuroendocrinology. While pursuing doctoral studies at the University of Texas at Austin, she completed her clinical fellowship year at Any Baby Can, where she worked for three years. Christine also worked as a Speech-Language Pathologist in Pflugerville, ISD in Texas. At both The University of Texas and Texas State University, Christine taught courses in communication disorders at the graduate and undergraduate level. Christine's primary research interests include bilingual language development and the assessment and intervention of bilingual children with language impairment. Publications include:

Bedore, L. M., Fiestas, C. E., Peña, E. D. (2006) Cross language comparisons of language use in Spanish and English of functionally bilingual and monolingual children, Bilingualism: Language and Cognition, Vol 9(3), 233-247.

Peña, E. D., Gillam, R. B., Malek, M. M., Ruiz-Felter, R., Resendiz, M., Fiestas, C. E., \& Sabel, T. (2006). Dynamic Assessment of School-Age Children’s Narrative Ability: An Experimental Investigation of Classification Accuracy, 
Journal of Speech, Language and Hearing Research, 49, 1037-1057.

Fiestas, C. E., \& Peña, E. (2004) Discourse in Bilingual Children: Task and Language Effects. Language, Speech and Hearing Services in Schools, 35, 155-166.

Permanent address: 12007 Scribe Drive, Austin, Texas 78759

This dissertation was typed by the author. 